\title{
Estimation of the Bid-Ask Spread and Its Components: A New Approach
}

\author{
Thomas J. George
}

Ohio State University

\section{Gautam Kaul}

The University of Michigan

\section{Nimalendran \\ University of Florida}

We show that time variation in expected returns and/or partial price adjustments lead to a downward bias in previous estimators of both the spread and its components. We introduce a new approach that provides unbiased and efficient estimators of the components of the spread. We find that between 77 and 97 percent of the downward bias in previous spread estimates is caused by time variation in expected returns. More importantly, the adverse-selection component, though significant, accounts for a much smaller proportion (8 to 13 percent) of the quoted spread at least for small trades, than the proportion (over 40 percent) previously reported in the literature. Order processing costs are the predominant component of quoted spreads.

\footnotetext{
We appreciate the comments and suggestions made by Victor Bernard, Michael Bradley, Jennifer Conrad, Harry DeAngelo, Stanley Kon, Gregory Niehaus. Michael Ryngaert, Nejat Seyhun, Chester Spatt, Robert Whaley, and seminar participants at Duke University, the University of Florida, The University of Michigan, and the University of North Carolina. We are especially grateful to Charles Lee for providing us with some data critical to our analysis, and to Donald Keim and the referee, Larry Glosten, for clarifying our thoughts on some important issues. We would also like to thank Patti Lampatter for preparing the manuscript. Partial funding for this project was provided by the School of Business Administration, The University of Michigan. All correspondence should be addressed to Gautam Kaul, School of Business Administration, The University of Michigan, Ann Arbor, MI 48109.
} 
In recent years, there has been growing interest in issues related to the microstructure of securities markets. An important component of the transaction costs faced by investors in financial securities is the bid-ask spread set by market makers. Following the seminal work of Demsetz (1968), many papers have attempted to model the cost components of the quoted spread: order-processing costs [Tinic (1972)], inventory holding costs [Amihud and Mendelson (1980) and Ho and Stoll (1981)], and adverse information costs [Copeland and Galai (1983) and Glosten and Milgrom (1985)].

The focus of recent research has been to estimate the bid-ask spread, and its components, using transaction returns. Under the assumption that the market maker faces only order-processing costs, Roll (1984) derives a simple measure of the spread based on the negative autocovariance of security returns. However, he finds that both weekly and daily estimates of the spread are downward biased. Glosten (1987) and Stoll (1989) show that the existence of adverse selection and/or inventory costs arising from the risk borne by a market maker could be two sources of the downward bias in spread estimates. Stoll (1989) finds that the quoted spread contains a large and statistically significant adverse-selection component, while the inventory cost component is small. Glosten and Harris (1988) also provide some evidence for the existence of adverse selection in securities markets.

However, all models of the spread, and empirical tests thereof, are based on the critical assumption that the only source of autocorrelation in transaction returns is the order-processing cost component of the Quoted spread. In this article, we show that positively autocorrelated time-varying expected returns lead to biases in estimators of both the spread and its components. We introduce a new approach that provides unbiased and efficient estimators of the components of the spread. This approach relies on constructing a spread measure based on the serial covariance of the difference between transaction returns and returns calculated using bid prices. This spread measure is not contaminated by any positive autocorrelation due to time-varying expected returns and/or short-run frictions in the market. The variance of this estimator is also much lower than the variance of existing spread estimators because the difference between transaction and bid returns does not contain an unexpected return component. We use our spread estimator and actual quoted spreads to obtain unbiased and precise estimates of the components of the bid-ask spread. Given that the history of bid/ask quotes is not available for a large number of stocks, we also provide an alternative approach to adjust transaction returns for time-varying expected returns. This approach provides more realistic estimates of the spread than previously reported. 
We use daily and weekly data of both AMEX/NYSE and NASDAQ stocks to test our hypotheses. There are several important aspects of our findings. Spread estimates based on transaction returns have a large downward bias, and between 77 and 97 percent of the bias is due to time-varying expected returns. The extent of both the bias and imprecision of transaction-return-based estimates of the spreads components is large. Also, contrary to the theory, the differencing interval (day/week) has a significant effect on estimates of the spread components.

Using our new approach, we provide both unbiased and precise estimates of the components of the spread. Both daily and weekly data provide identical estimates, and the evidence suggests that the adverse-selection component, though significant, comprises only 8 to 13 percent of quoted spreads. This magnitude is less than one third the estimate of over 40 percent reported in the literature. We also find no evidence for the inventory cost component. Hence, orderprocessing costs are the predominant component of quoted spreads. If the proportions of the spread due to its various components remain fixed with changes in order size, then our estimates of the components are valid for all order sizes. However, if the adverse-selection component is disproportionately larger for large trades, then our 8 to 13 percent estimate for this component will apply only to small trades (and will provide a lower bound for the adverse-selection spread for large trades).

In Section 1, we present a simple model of the bid-ask spread. In Section 2, we discuss the biases in previous spread estimators, and present two alternative estimators. In Section 3, we introduce our methodology, which provides unbiased and efficient estimators of the components of the spread. In Section 4, we report and analyze the empirical evidence. We discuss the sensitivity of our results to changes in the assumptions underlying our model and estimation techniques in Section 5, and we conclude with a brief summary in Section 6. All proofs are contained in the Appendix.

\section{The Model}

The model used in this article is similar to the one presented in Glosten and Harris (1988). We decompose the quoted spread into an order-processing cost component and an adverse-selection component. The order-processing cost component can be viewed as the compensation to the market maker for providing liquidity services. Being transitory in nature, this component causes price changes to be negatively autocorrelated [see Glosten (1987), Niederhoffer and Osborne (1966), and Roll (1984)]. The adverse-selection component, 
on the other hand, exists because a market maker may trade with investors who possess superior information. This component represents the market maker's profits from uninformed traders who compensate him for the expected losses to informed traders [see Bagehot (1971), Copeland and Galai (1983), and Glosten and Milgrom (1985)].

Following Glosten and Milgrom (1985), we view the adverse-selection component as the revision in the market maker's expectation of the value of a stock resulting from the submission of an order. Conditional on a buy (sell) order for a stock, the market maker will revise his expectation of the stock's future value upward (downward). However, since the revision in expectations, conditional on order type, can be anticipated, a rational market maker will incorporate such revisions into his bid and ask prices. One of these prices is subsequently observed when an order is filled.

Having discussed the major components of the spread, we now present a more formal model. For simplicity, we make two assumptions. First, we assume that all trades are of unit size, or that the spread is independent of trade size. Second, the ex ante probabilities of trades at the bid and ask are equal. Since these assumptions may be restrictive, we discuss their implications for our results in Section 4.

The following notation is used in describing our model:

$$
\begin{aligned}
P_{t}= & \text { observed price of transaction } t, \\
Q_{t}= & \text { unobservable indicator for the bid-ask classification of } \\
& P_{i}\left(Q_{i}=+1, \text { if transaction } t \text { is at the ask, and } Q_{t}=-1\right. \text {, if } \\
& \text { it is at the bid), } \\
M_{t}= & \text { unobservable "true" price that reflects all publicly avail } \\
& \text { able information immediately following transaction } t, \\
E_{t}= & \text { unobservable expected return for the period between } \\
& \text { transactions } t-1 \text { and } t \text {, based on all public information } \\
& \text { up to transaction } t-1, \\
U_{t}= & \text { unobservable innovation in "true" prices due to the arrival } \\
& \text { of public information between transactions } t-1 \text { and } t, \\
s_{q}= & \text { quoted spread of the market maker, } \\
\pi= & \text { unobservable proportion of the quoted spread due to } \\
& \text { order-processing costs, } \\
1-\pi= & \text { unobservable proportion of the quoted spread due to } \\
& \text { adverse selection. }
\end{aligned}
$$

\footnotetext{
1 Amihud and Mendelson (1980) and Ho and Sto11 (1981) argue than inventory holding costs arising from the risk borne by a market maker could also comprise an important part of quoted spreads. However, Stoll (1989) finds that these costs constitute only 10 percent of quoted spreads. Consequently, we do not model this component of the spread, but we do provide further evidence that it is a negligible part of the spread.
} 
Our model for transaction prices can then be written as

$$
\begin{aligned}
P_{t} & =M_{t}+\pi\left(s_{q} / 2\right) Q_{n} \\
M_{t} & =E_{t}+M_{t-1}+(1-\pi)\left(s_{q} / 2\right) Q_{t}+U_{r}
\end{aligned}
$$

An important departure from previous models of the spread is that we allow the "true" expected return of a security, $E_{t}$, to vary through time. Market efficiency does not imply any restrictions on expected returns, and there is growing evidence that conditional expected returns of portfolios of stocks vary through time and are positively autocorrelated [see, e.g., Conrad and Kaul (1988, 1989) and Keim and Stambaugh (1986)]. More importantly, Conrad, Kaul, and Nimalendran (1990) show that individual security returns, though negatively autocorrelated, also contain a statistically identifiable, positively autocorrelated, expected return component. Therefore, $\operatorname{Cov}\left(\boldsymbol{E}_{n}\right.$ $\left.E_{t-1}\right)>0$. 'The presence of a positively autocorrelated, expected return component has important implications for estimators of both the level of spread (see Section 2.2) and its components (see Section 3). Also, note that any source of positive autocovariance will lead to a downward bias in existing spread measures. In particular, short-term partial price adjustments due to smoothing effects by market makers could lead to positive autocorrelation in returns [see, e.g., Amihud and Mendelson (1987) and Cohen et al. (1986)]. For expositional simplicity, however, we presume that any (or all) positive autocorrelation in security returns is induced by time-varying expected returns.

\section{Measures of the Spread}

\subsection{Existing measures}

Since all existing measures of the spread are based on the covariance of successive transaction price changes, we first analyze the serial covariance of price changes within the context of our model. We then indicate the major sources of bias in existing measures of the quoted spread. For convenience, we use continuously compounded returns and proportional spreads in deriving the autocovariance based spread measures [Glosten (1987) and Roll (1984)].

Let $\boldsymbol{R}_{\boldsymbol{m}}$ lbe the continuously compounded return of security $i$ based on transaction prices at time $\boldsymbol{t}-\mathbf{1}$ and $\boldsymbol{t}$. 'From Equations (1) and (2), it follows that

$$
R_{m}=E_{u t}+B_{u t}+U_{t n}
$$

where

$$
B_{t s}=\pi_{t}\left(s_{q d} / 2\right)\left[Q_{t t}-Q_{t r-1}\right]+\left(1-\pi_{j}\right)\left(s_{q v} / 2\right) Q_{t r}
$$


The serial covariance of transaction returns can, therefore, be written as

$$
\operatorname{Cov}\left(R_{r m}, R_{r n-1}\right)=\operatorname{Cov}\left(E_{t r} E_{b r-1}\right)-\pi, s_{q}^{2} / 4
$$

The expression in Equation (4) will form the basis of our analysis. Given Equation (4), the relation between the serial covariance of transaction returns and the quoted spread is

$$
2 \sqrt{-\left[\operatorname{Cov}\left(R_{t m} R_{t r-1}\right)-\operatorname{Cov}\left(E_{t t}, E_{t r-1}\right)\right]}=\sqrt{\pi S_{q r}}
$$

Roll (1984) derives a simple measure of the spread based on two important assumptions: (1) The expected return of a security is constant through time, i.e., $\boldsymbol{E}_{\boldsymbol{u}}=\boldsymbol{E}_{\boldsymbol{t}} \boldsymbol{\nabla} \boldsymbol{t}$, and (2) there is no adverse selection in securities markets, i.e., $, \boldsymbol{\pi}_{\boldsymbol{i}}=\mathbf{1}, \boldsymbol{\forall}$. Under these assumptions, Roll's measure of the quoted spread follows directly from Equation (5):

$$
s_{t}=2 \sqrt{-\operatorname{Cov}\left(R_{i \pi n}, R_{r n-1}\right)} .
$$

Glosten (1987) shows that if quoted spreads contain an adverseselection component, then Roll's spread measure, $s_{t}$, will understate the true quoted spread, $\boldsymbol{s}_{\boldsymbol{q} \text {. }}$. This can be seen by a direct comparison, of Equations (5) and (6): if $\boldsymbol{x}_{\boldsymbol{1}}<\mathbf{1}$, then Roll's measure will be downward biased even if $\operatorname{Cov}\left(\boldsymbol{E}_{t n} \boldsymbol{E}_{\boldsymbol{u}-\mathbf{1}}\right)=\mathbf{0}$. However, time-varying expected returns will also lead to a downward bias in $s_{t}$. In fact, if $\operatorname{Cov}\left(\boldsymbol{E}_{t \mathrm{n}} \boldsymbol{E}_{t t-1}\right)>\boldsymbol{\pi}_{\boldsymbol{\lambda}}\left(\boldsymbol{s}_{q \boldsymbol{q}}^{\mathbf{2}} / \mathbf{4}\right)$, spread estimates based on transaction returns could actually be negative [see Equation (4)]. Roll (1984) finds that approximately 50 and 35 percent of spread estimates obtained from daily and weekly data, respectively, are negative.

\subsection{Alternative Spread Measures}

To analyze the implications of time-varying expected returns, we assume that the expected return of a particular security $i$ follows a first-order autoregressive process, that is,

$$
E_{t t}=\mu_{i}+\phi_{t o} E_{t t-1}+\epsilon_{t r} \quad 1>\phi_{t o}>0 .
$$

The assumption of an $\mathrm{AR}(1)$ process for $E_{i t}$ is based on the evidence in Conrad and Kaul (1988). However, $E_{i t}$ is unobservable. We therefore present two alternative techniques to take into account time variation in $E_{i t}$.

Method 1. The first technique uses the methodology introduced in Conrad, Kaul, and Nimalendran (1990) to extract the expected return of an individual security. Specifically, for each security we estimate a regression of the form 
where $\boldsymbol{R}_{\boldsymbol{m}}$ the continuously compounded transaction return of security $i$ in period $\boldsymbol{E}_{p t}=\boldsymbol{\mu}_{p}+\boldsymbol{\phi}_{p e} \boldsymbol{E}_{p t-1}+\boldsymbol{\epsilon}_{p x}:$ is the expected return of an equal-weighted size-based portfolio to which security $i$ belongs, and $\boldsymbol{\eta}_{\boldsymbol{t}}$ is a disturbance term.

We use the disturbances of Regression (8) to define our adjusted measure of the spread

$$
s_{1 t}=2 \sqrt{-\operatorname{Cov}\left(\eta_{t i n} \eta_{t m-1}\right)}
$$

The intuition behind $\boldsymbol{s}_{\mathbf{1}} \boldsymbol{i}$ can be seen by examining the properties of regression (8). Under the assumption that the bid-ask error components of securities are cross-sectionally uncorrelated, each $\boldsymbol{\gamma}_{\mathbf{1}}$ in regression (8) is determined primarily by the average covariance of security i's expected return with the expected returns of the remaining securities in portfolio $\mathrm{p}$. We would suspect that the expected returns of all securities within a particular portfolio are positively correlated, or $\operatorname{Cov}\left(\boldsymbol{E}_{t \mathrm{~s}} \boldsymbol{E}_{\boldsymbol{\prime} \boldsymbol{z}}\right)>\mathbf{0}$. Consequently, the (average) positive covariance that is measured by $\boldsymbol{\gamma}_{\mathbf{1}}{ }^{\prime}$ ' will enable $E_{p t}$ to extract the expected return from a particular security's realized return. If $E_{p t}$ is a perfect proxy for $E_{i p}$, regression (8) will completely purge realized returns of the time-varying expected return component. For small market value firms, $\boldsymbol{R}_{\boldsymbol{r} \boldsymbol{\pi}}$ icould be spuriously correlated with $E_{p t}$ as a result of nonsynchronous trading. However, Conrad, and Kaul (1991) show that nonsynchronous trading has little effect on the time-series properties of even daily returns of securities that trade each day [see also Lo and MacKinlay (1990)].

Method 2. Our second method for extracting $E_{i t}$ requires that, apart from transaction prices, bid and ask quotes are also available for each security. Let $\mathrm{PB}_{t}$ be the bid quote subsequent to transaction $t .^{2}$ Then the return calculated from bid quotes, $R_{i B}$, is

$$
R_{t Q t}=E_{t t}+\left(1-\pi_{)}\right)\left(s_{q d} / 2\right) Q_{i t}+U_{t r}
$$

Now define the difference between $\boldsymbol{R}_{\boldsymbol{r} \boldsymbol{r}}$ and $\boldsymbol{R}_{\boldsymbol{B} \boldsymbol{B}}$ as $\mathbf{R D}_{\boldsymbol{d}}$, where

$$
\mathrm{RD}_{u}=\pi_{1}\left(s_{q d} / 2\right)\left[Q_{t}-Q_{u-1}\right] \text {. }
$$

The serial covariance of $\mathrm{RD}_{i t}$ therefore, is

$$
\operatorname{Cov}\left(\mathrm{RD}_{\mu m} \mathrm{RD}_{\mu-1}\right)=-\pi_{i}^{2}\left(s_{q 1}^{2} / 4\right) \text {. }
$$

Our second spread measure, $\boldsymbol{s}_{\mathbf{2} \boldsymbol{n}}$ can then be written as

$$
s_{21}=2 \sqrt{-\operatorname{Cov}\left(\mathrm{RD}_{u t} \mathrm{RD}_{u t-1}\right)}=\pi_{s} s_{q t}
$$

\footnotetext{
2 If bid/ask quotes and transaction prices are measured simultaneously, our analysis will be altered. We thank the referee for drawing our attention to this important issue. See Section 5.2 for a further discussion of this issue.
} 
There are two important differences between Roll's spread measure, $s_{i}$, and our second measure, $\boldsymbol{s}_{24}$. First, and most importantly, by construction the serial covariance of $\mathrm{RD}_{i t}$ is unaffected by any positive autocovariance induced by time-varying expected returns and/or frictions in the trading process. This occurs because both $\boldsymbol{R}_{\boldsymbol{r} \boldsymbol{r}}$ and $\boldsymbol{R}_{\boldsymbol{\Delta} \boldsymbol{b t}}$ contain $E_{i}$, and hence the difference between them is purged of all the effects of time-varying expected returns; Second, if adverse selection exists in securities markets, that is, $\pi_{1}<1$, it will lead to a greater downward bias in $\boldsymbol{s}_{\mathbf{2}}$ than in $\boldsymbol{s}_{\mathbf{i}}$ because the former is downward biased by a factor of $\boldsymbol{\pi}_{n}$ whereas the latter is biased by a factor of $\sqrt{\pi_{1}}$.

The following properties of our spread measures highlight their important characteristics. (The proofs are in Appendix A.)

Property A1. Suppose there is no adverse selection in securities markets. Under the assumption that $E_{i t}$ and $E_{p t}$ both follow an $A R(1)$ process with the same autoregressive parameter $^{3} \boldsymbol{\phi} \in(0,1)$,

$$
\boldsymbol{s}_{\boldsymbol{q}}=\boldsymbol{s}_{\mathbf{2}} \geq \boldsymbol{s}_{\mathbf{1} \boldsymbol{t}}
$$

And the downward bias in $s_{1 i}$ decreases to zero if the variance of the error in using $E_{p t}$ as a proxy for $E_{i t} \operatorname{Var}\left(\boldsymbol{E}_{\boldsymbol{\alpha t}}-\boldsymbol{\gamma}_{\boldsymbol{n}} \boldsymbol{E}_{\boldsymbol{p} \boldsymbol{\nu}}\right)$, decreases to zero (i.e., $E_{p t}$ is a perfect proxy for $E_{i t}$.

Property A2. If bid and/or ask quotes are not available, filtering returns with $E_{p t}$ always reduces the bias in Roll's spread estimator, $s_{i}$.

Since $\boldsymbol{s}_{\mathbf{2}}$ by construction presumes that bid/ask quotes, and hence $\boldsymbol{s}_{q+}$ are observable, there is no need to estimate spreads under these circumstances. However, there are three important reasons for introducing $\boldsymbol{s}_{\mathbf{2} \boldsymbol{r}}$. First, $\boldsymbol{s}_{\boldsymbol{z} \boldsymbol{\ell}}$ is unaffected by any positive autocorrelation in security returns due to $E_{i t}$. Hence, under the assumption of no adverse selection, $\boldsymbol{s}_{\mathbf{2}}-\boldsymbol{s}_{\mathbf{f}}$ measures the full extent of the downward bias in Roll's spread measure due to time-varying expected returns. Second, $\boldsymbol{s}_{\mathbf{2}} \boldsymbol{i}-\boldsymbol{s}_{\mathbf{1}}$ measures the extent to which Method 1 does not fully correct for the downward bias in $s_{i}$. Finally, and most importantly, $\boldsymbol{s}_{\mathbf{z} \boldsymbol{i}}$ i critical to obtaining unbiased and precise estimates of the components of the spread (see Section 3).

\footnotetext{
3 The assumption that the expected returns of all securities within a particular size-based portfolio have identical autoregressive parameters is made to ensure that $E_{p t}$ does not induce some spurious negative autocorrelation In - It can be shown that if $E_{p t}$ has an autoregressive parameter, sufficiently greater than the autoregressive parameter of $\boldsymbol{E}_{\boldsymbol{m}} \boldsymbol{\phi}_{\boldsymbol{m}}$ then such spurious autocorrelation can result. In Section 5.5, we provide evidence which suggests that use of $E_{p t}$ filter $R_{i T t}$ generally does not induce spurious negative autocorrelation in
} 


\section{Components of the Bid-Ask Spread}

In this section, we describe a methodology to decompose the spread into its various components. This methodology is similar in spirit to the one used by Stoll (1989). Suppose the quoted spread, $s_{q i}$, is observable. Then, conditional on the observable quoted spread, we can decompose it into the order processing cost and adverse-selection components by regressing the spread measures on the quoted spreads. Since true serial covariances are not observable, we use estimates of the spread measures instead. Let $\hat{\boldsymbol{s}}_{\boldsymbol{t}} \hat{\boldsymbol{s}}_{\mathbf{1}}$ and $\hat{\boldsymbol{s}}_{\mathbf{2}}$ be the estimators of the three serial covariance measures of the spread that, in turn, provide estimates used in the following regressions:

$$
\begin{aligned}
& \hat{s}_{t s}=\alpha_{1}+\beta_{1} s_{q t r}+\epsilon_{t r} \\
& \hat{s}_{1 t}=\alpha_{1 t}+\beta_{1} s_{q t t}+\epsilon_{1 t r} \\
& \hat{s}_{2 t t}=\alpha_{2 t}+\beta_{2 t} s_{q t}+\epsilon_{2 t r}
\end{aligned}
$$

In the empirical tests, we estimate these regressions cross-sectionally for firms within a particular portfolio. Under the assumption that the quoted spread, $s_{q i}$, is observed without error (or that any measurement error is purely random), estimators of the parameters of the three regressions have the following properties. (The proofs are in Appendix B.)

Property B1. The estimator of the slope coefficient, $\hat{\boldsymbol{\beta}}_{20}$ of regression $(15 c)$ is an unbiased measure of $\boldsymbol{\pi}_{\phi}$ the proportion of the spread due to order-processing costs [i.e., $\boldsymbol{E}\left(\hat{\boldsymbol{\beta}}_{2 t}\right)=\boldsymbol{\beta}_{\boldsymbol{z}}=\boldsymbol{\pi}_{1}$ ]. Also, $\boldsymbol{E}\left(\hat{\boldsymbol{\alpha}}_{\boldsymbol{z}}\right)=\boldsymbol{\alpha}_{\boldsymbol{z}}=$ 0 , and both $\hat{\boldsymbol{\alpha}}_{\boldsymbol{2}}$ and $\hat{\boldsymbol{\beta}}_{\boldsymbol{z}}$ are efficient estimators.

Property B2. (a) If the specification errors in $\hat{\boldsymbol{s}}_{\boldsymbol{t}}$ and $\hat{\boldsymbol{s}}_{\boldsymbol{u}}$, are correlated with $s_{q i}$ then $\hat{\boldsymbol{\beta}}_{\boldsymbol{i}}$ and $\hat{\boldsymbol{\beta}}_{\boldsymbol{w}}$ are upward (downward) biased depending on whether the errors in $\hat{\boldsymbol{s}}_{\boldsymbol{t}}$ and $\hat{\boldsymbol{s}}_{\boldsymbol{u}}$ are positively (negatively) correlated with $s_{q i}$ Biases in $\hat{\boldsymbol{\beta}}_{\text {, and }} \hat{\boldsymbol{\beta}}_{\mathbf{1}}$ in turn, lead to biases in the opposite direction in $\hat{\boldsymbol{\alpha}}_{\boldsymbol{1}}$ and $\hat{\boldsymbol{\alpha}}_{\mathbf{1}}$

(b) If the specification errors in $\hat{\boldsymbol{s}}_{\boldsymbol{\boldsymbol { t }}}$ and $\hat{\boldsymbol{s}}_{\boldsymbol{u}}$ (which are systematically related to time variation in expected returns) are independent of $\boldsymbol{s}_{q,} \boldsymbol{E}\left(\hat{\boldsymbol{\beta}}_{\mathfrak{j}}\right)=\boldsymbol{\beta}_{1}=\sqrt{\pi_{1}}$ and $\boldsymbol{E}\left(\hat{\boldsymbol{\beta}}_{1}\right)=\boldsymbol{\beta}_{1 t}=\sqrt{\boldsymbol{\pi}_{r}}$ Also, $\boldsymbol{E}\left(\hat{\boldsymbol{\alpha}}_{\nu}\right)=\boldsymbol{\alpha}_{1}$ and $\boldsymbol{E}\left(\hat{\boldsymbol{\alpha}}_{1}\right)=\boldsymbol{\alpha}_{\boldsymbol{z}}$ measure the downward bias in $\hat{\boldsymbol{s}}_{1}$ and $\hat{\boldsymbol{s}}_{\mathbf{1}}$, due to timevarying expected returns. Moreover, $\boldsymbol{E}\left(\hat{\boldsymbol{\alpha}}_{\boldsymbol{\nu}}\right)<\boldsymbol{E}\left(\hat{\boldsymbol{\alpha}}_{\boldsymbol{1}}\right) \leq \boldsymbol{E}\left(\hat{\boldsymbol{\alpha}}_{21}\right)=0$, with $\boldsymbol{E}\left(\hat{\boldsymbol{\alpha}}_{\boldsymbol{1}}\right)$ approaching zero as the variance of the error in using $E_{p t}$ as a proxy for $E_{i t}$ decreases to zero.

Property B3. The sampling variances of ' $\hat{\boldsymbol{s}}_{\mathbf{1}}$ and $\hat{\boldsymbol{s}}_{\mathbf{z}}$ are substantially larger than the sampling variance of $\hat{\boldsymbol{s}}_{2 t}$ Consequently, the $R^{2}$ 's of 
regressions (15a) and (15b) will be significantly lower than the $R^{2}$ of regression (15c), and estimators of the parameters of these regressions are inefficient compared to $\hat{\boldsymbol{\alpha}}_{2 t}$ and $\overline{\boldsymbol{\beta}}_{2 \boldsymbol{t}}$. This problem will be more severe in weekly, as opposed to daily, data, and more severe for larger than for smaller firms. However, here again extraction of $E_{i t}$ from transaction returns will make the sampling variances of ' $\hat{\boldsymbol{\alpha}}_{\boldsymbol{\prime}}$ and $\hat{\boldsymbol{\beta}}_{\boldsymbol{z}}$, lower relative to the sampling variances of $\hat{\boldsymbol{\alpha}}_{\boldsymbol{s}}$ and $\overline{\boldsymbol{\beta}}_{\boldsymbol{r}}$

Hence, the estimators of the parameters of regression (15c) have very desirable properties. However, previous researchers have attempted to infer the components of the spread based exclusively on the time-series properties of transaction returns [see, e.g., Glosten and Harris (1988) and Stoll (1989)]. Using transaction returns to infer the components of the quoted spread amounts to, within our framework, estimating regression (15a). The properties of the estimators of the parameters of regression (15a) indicate that inferences about both the level of the spread and its components based on transaction returns may be misleading.

Estimators $\hat{\boldsymbol{\alpha}}_{\boldsymbol{t}}$ and $\hat{\boldsymbol{\beta}}_{\boldsymbol{t}}$ could be biased because $\hat{\boldsymbol{s}}_{\boldsymbol{t}}$ contains specification errors that could be systematically related to the level of the quoted spread, $\boldsymbol{s}_{\boldsymbol{q} \boldsymbol{t}}$ And $\hat{\boldsymbol{\alpha}}_{\boldsymbol{1}}$ and $\hat{\boldsymbol{\beta}}_{\boldsymbol{q}}$ are inefficient because $\hat{\boldsymbol{s}}_{\boldsymbol{t}}$ is based on transaction returns that contain a huge unexpected return component, $U_{i t}$ On the other hand, since : $\hat{\boldsymbol{s}}_{\mathbf{2}}$ is based on $\mathrm{RD}_{i t}$, which does not contain either $E_{i t}$ or $\boldsymbol{U}_{\boldsymbol{t}} \hat{\boldsymbol{\alpha}}_{2 \boldsymbol{t}}$ and $\hat{\boldsymbol{\beta}}_{2 t}$. will be both unbiased and efficient. Estimators of the parameters of regression (15b) will also be inefficient compared to $\hat{\boldsymbol{\alpha}}_{2 s}$ and $\overline{\boldsymbol{\beta}}_{2 n}$ but use of a good proxy for $E_{i t}$ could not only eliminate the biases in $\hat{\boldsymbol{\alpha}}_{\mathbf{1}}$ and $\tilde{\boldsymbol{\beta}}_{\mathbf{1 0}}$ but will also increase their efficiency. Fortunately, since $\hat{\boldsymbol{\alpha}}_{\mathbf{2}}$ and $\hat{\boldsymbol{\beta}}_{\mathbf{2}}$, are unbiased and efficient, they can be used to evaluate the potential biases in, and relative efficiency of, $\boldsymbol{\beta}_{1}$ and $\boldsymbol{\beta}_{\mathfrak{1}}$ (and $\hat{\boldsymbol{\alpha}}_{1}$ and $\hat{\boldsymbol{\alpha}}_{\mathbf{1}}$ ). Finally, note that $\overrightarrow{\boldsymbol{\beta}}_{\mathbf{2}}$ provides estimates of $\pi_{n}$ while both $\hat{\beta}_{i}$ and $\hat{\beta}_{18} 1$ measure $\sqrt{\pi_{r}}$.

\section{Empirical Evidence}

\subsection{Data description}

The tests in this article use the Center for Research in Security Prices (CRSP) daily master files for both the AMEX/NYSE and NASDAQ firms to compute individual security and portfolio returns. For the AMEX/NYSE stocks, our data cover the period between January 1963 and December 1985. However, for the NASDAQ firms we have a much shorter sample period, January 1983 to December 1987, since transaction prices and closing bid and ask quotes are available for NMS issues on a regular basis only after October 1, 1982. 
An important feature of the NASDAQ data is that the transaction prices are for the last trade of a particular day, but the bid/ask quotes are as of the close of each trading day. Hence, as assumed in Sections 2 and 3, the bid quotes are typically subsequent to the last transaction on any given day. The only occasions on which the transaction and bid prices are measured simultaneously is when market-at-close orders are placed, and there is evidence to suggest that such orders are quite infrequent.

We break up both the AMEX/NYSE and NASDAQ sample periods into subperiods, and sort firms into portfolios based on market value (number of shares outstanding times price per share) at the beginning of each subperiod. ${ }^{4}$ For the AMEX/NYSE firms, we have 23 one-year subperiods and-because of the shorter sample period-we have 10 six-month subperiods for the NASDAQ stocks. We use both daily and weekly data to test our main hypotheses. It is important to note that since autocovariance-based spread measures suffer from small-sample bias [see Harris (1996) and Roll (1984)], use of high frequency data is more appropriate. However, Glosten (1987) and Roll (1984) show that the differencing interval should not affect estimates of the orderprocessing cost and adverse-selection components of the quoted spread. Hence, we use weekly data (in addition to daily data) primarily to test this important property of models of the bid-ask spread.

Daily and weekly returns for each security are calculated from the prices of the last transaction of each day (week). The weekly return of each security is computed from Wednesday to Wednesday. For each daily (weekly) period, only securities that have transaction prices available for both endpoints of the measurement interval are sorted into portfolios based on market value. Returns of securities in each portfolio are then equally weighted to form daily and weekly portfolio returns.. All portfolio returns are continuously compounded. The AMEX/NYSE stocks are divided into five portfolios, while the NASDAQ firms are sorted into three portfolios. For our analysis, we also require returns of individual securities that belong to the various sizebased portfolios. To ensure that we have an unbroken series of continuously compounded returns available for each security in each subperiod, we only retain securities that have transaction prices available for all endpoints of the measurement interval (day or week) within a particular subperiod. ${ }^{5}$ For NASDAQ firms, we also calculate

\footnotetext{
${ }_{4}^{4}$ Our NASDAQ results suggest that sorting firms by size or trading volume would lead to similar conclusions.

${ }^{5}$ Our sampling procedure leads to the exclusion of a number of small firms from the sample. This would not affect our results because we estimate spreads of the sampled securities and then compare them to their own quoted spreads. Estimates of the components of the spread also appear to be robust to our sampling procedure because they are the same (in percentage terms) across firms of different market value.
} 
daily and weekly continuously compounded returns based on closing bid prices.

Finally, estimation of $\boldsymbol{s}_{\mathbf{1}}$, requires forecasts of portfolio expected returns, $E_{p t}$ [see Equation (8)]. We use the methodology in Conrad and Kaul (1988) to extract the expected portfolio returns from realized returns. In the weekly sample, an AR(l) process for expected returns appears to be well-specified. For the daily data, however, portfolio expected returns appear to follow a higher-order autoregressive process. Accordingly, we estimate more complicated models so as to ensure that the unexpected return series, $\boldsymbol{R}_{\boldsymbol{p s}}-\boldsymbol{E}_{\boldsymbol{p} \boldsymbol{s}}$ behaves like white noise.

\subsection{Bias due to time variation in expected returns}

AMEX/NYSE firms. Table 1 reports average weekly and daily estimates of the bid-ask spread for AMEX/NYSE stocks using both transaction returns and returns adjusted for time variation in expected returns, $\hat{\boldsymbol{s}}_{\mathbf{1}}$ and $\hat{\boldsymbol{s}}_{\mathbf{1}}$ We present average estimates for each portfolio and for all firms in the sample. The second column reports the sample size over the entire 1963 to 1985 period for each portfolio. Column 3 shows the average market values of the firms in the sample. These. averages are based on the 23 year-end market values, and exhibit the wide range of different capitalization firms in the sample.

Each estimate of $\boldsymbol{s}_{\boldsymbol{i}}$ and $\boldsymbol{s}_{\mathbf{1}}$ is calculated for individual firms during each of the 23 one-year subperiods. The individual-firm estimates are then averaged across firms within each portfolio to obtain subperiod averages. Each reported estimate is the grand average of the subperiod averages. Table 1 also includes standard errors of the estimates based on the distribution of the 23 subperiod averages, under the assumption that these averages are independent and identically distributed. Since the number of firms in a particular portfolio varies over the subperiods, both the grand averages and their standard errors are obtained by weighting each subperiod's average by the number of firms in that subperiod. We follow this procedure in all the subsequent tables.

Panel A contains the mean (percent) weekly spread estimates. The average estimates of $s$ are all positive and statistically significant, and range between 3.265 and 0.700 . The average value of 1.396 for all firms is close to the weekly estimate of 1.74 obtained by Roll (1984). Also, in line with Roll's findings, 35.3 percent (compared to 34.8 percent) of all estimates are negative. The adjusted spread estimates, $\hat{\boldsymbol{s}}_{\mathbf{1}}$, rreflect the large downward bias present in weekly spread estimates based on transaction returns: they vary between 4.455 and 1.191, with an average for all firms of 2.293. The average difference between $\hat{\boldsymbol{s}}_{\mathbf{1}}$ 
Table 1

Weekly and dally estlmates of the bid-ask spread for AMIX and NYSE stocks sorted by market ralue, 1963-1985

\begin{tabular}{|c|c|c|c|c|c|c|c|}
\hline Porfolio & $\begin{array}{l}\text { Sample } \\
\text { size }\end{array}$ & $\begin{array}{l}\text { Average } \\
\text { market } \\
\text { value } \\
\text { (in } 8 \\
\text { million) }\end{array}$ & $\begin{array}{c}s \\
(\%)\end{array}$ & $\begin{array}{l}\text { No. of } \\
\text { negative } \\
\text { spreads }\end{array}$ & $\stackrel{s}{(\%)}$ & $\begin{array}{l}\text { No. of } \\
\text { negative } \\
\text { spreads }\end{array}$ & $\xi_{i}-\xi$ \\
\hline \multicolumn{8}{|c|}{ A. Weekly estimates } \\
\hline $\begin{array}{l}1 \\
\text { (Smallest) }\end{array}$ & 4,195 & 7.096 & $\begin{array}{c}3.265 \\
(0.194)\end{array}$ & 1,085 & $\begin{array}{c}4.455 \\
(0.150)\end{array}$ & 678 & $\begin{array}{c}1.190 \\
(0.134)\end{array}$ \\
\hline 2 & 6,169 & 23.947 & $\begin{array}{c}2.040 \\
(0.156)\end{array}$ & 1,943 & $\begin{array}{c}3.141 \\
(0.180)\end{array}$ & 1,291 & $\begin{array}{c}1.101 \\
(0.141)\end{array}$ \\
\hline 3 & 8,020 & 63.558 & $\begin{array}{c}1.318 \\
(0.138)\end{array}$ & 2,812 & $\begin{array}{c}2.430 \\
(0.171)\end{array}$ & 1,795 & $\begin{array}{c}1.112 \\
(0.143)\end{array}$ \\
\hline 4 & 9,223 & 185.342 & $\begin{array}{c}0.964 \\
(0.125)\end{array}$ & 3,451 & $\begin{array}{c}1.858 \\
(0.130)\end{array}$ & 2,331 & $\begin{array}{c}0.894 \\
(0.113)\end{array}$ \\
\hline $\begin{array}{l}5 \\
\text { (largest) }\end{array}$ & 10,354 & 1447.393 & $\begin{array}{c}0.700 \\
(0.097)\end{array}$ & 4,102 & $\begin{array}{c}1.191 \\
(0.070)\end{array}$ & 3,162 & $\begin{array}{c}0.491 \\
(0.109)\end{array}$ \\
\hline All frms & 37,961 & 457.916 & $\begin{array}{c}1.396 \\
(0.096)\end{array}$ & 13,393 & $\begin{array}{c}2.293 \\
(0.113)\end{array}$ & 9,257 & $\begin{array}{c}0.897 \\
(0.063)\end{array}$ \\
\hline \multicolumn{8}{|c|}{ B. Daily estimates } \\
\hline (Smallest) & 3,306 & 7.945 & $\begin{array}{c}0.980 \\
(0.232)\end{array}$ & 1,311 & $\begin{array}{c}1.426 \\
(0.207)\end{array}$ & 998 & $\begin{array}{c}0.446 \\
(0.064)\end{array}$ \\
\hline 2 & 4,825 & 22.048 & $\begin{array}{c}0.429 \\
(0.149)\end{array}$ & 2,200 & $\begin{array}{c}0.875 \\
(0.146)\end{array}$ & 1,673 & $\begin{array}{c}0.446 \\
(0.063)\end{array}$ \\
\hline 3 & 6,678 & 61.782 & $\begin{array}{c}-0.014 \\
(0.088)\end{array}$ & 3,545 & $\begin{array}{c}0.463 \\
(0.101)\end{array}$ & 2,650 & $\begin{array}{c}0.477 \\
(0.066)\end{array}$ \\
\hline 4 & 8,256 & 175.902 & $\begin{array}{c}-0.300 \\
(0.068)\end{array}$ & 5,003 & $\begin{array}{c}0.152 \\
(0.066)\end{array}$ & 3,784 & $\begin{array}{c}0.452 \\
(0.057)\end{array}$ \\
\hline $\begin{array}{l}5 \\
\text { (Largest) }\end{array}$ & 9,986 & 1422.524 & $\begin{array}{c}-0.557 \\
(0.061)\end{array}$ & 7,242 & $\begin{array}{c}-0.153 \\
(0.041)\end{array}$ & 5,709 & $\begin{array}{c}0.404 \\
(0.055)\end{array}$ \\
\hline All firms & 33,051 & 490.236 & $\begin{array}{c}-0.085 \\
(0.067)\end{array}$ & 19,301 & $\begin{array}{c}0.356 \\
(0.066)\end{array}$ & $.14,814$ & $\begin{array}{c}0.441 \\
(0.027)\end{array}$ \\
\hline
\end{tabular}

The percent spread is calculated as $z_{m}=200 \sqrt{-\mathrm{Cbv}_{m}}$ where $\operatorname{cov} v_{m}$ is the autocovariance of returns in period $t$ for security $t$. Spread estimates $s$ and $\hat{L}_{1}$ are based on transaction returns, $R_{m}$ and returns adjusted for time variation in expected returns, $\eta_{0}$ respectively. The individual-firm spread estimates are averaged across firms within each porfolio to obvin subperiod averages. Each reported number is the weighted grand average of the 23 subperiod averages. The last column reports the difference, $\xi_{1}-\xi$ between the two estimates. The weighted standard errors, reported in parentheses, are based on the distribution of the subperiod averages.

and $\hat{\boldsymbol{s}}_{1}$ ranges between 1.190 and 0.491 , with an average value for all firms of 0.861 . All of these differences are statistically significant at conventional significance levels (see the last column of Table 1). ${ }^{6}$

Panel B reports daily average estimates of the two spread measures. For all firms taken together, the estimate of $s$ is indistinguishable from zero, and large firms (portfolios 4 and 5) have significantly negative

\footnotetext{
${ }^{6}$ Keim (1989) shows that between 1964 and 1972, CRSP did not employ its standard convention for identifying nontrading by a negative price. As a result, many prices that were actually averages of bid and ask prices incorrectly entered the sample as transaction prices. This could lead to downward bias in $\$$ However, our estimates of $s$ are very similar in the 1964-1972 and 1973-1985 periods: 1.469 versus 1.297. Hence, this potential source of downward bias in $\boldsymbol{s}$ does not appear to be Important.
} 
mean spread estimates. Adjusting individual security returns for timevarying expected returns again leads to a statistically significant increase in all spread estimates (see the last column). The average values of $\hat{\boldsymbol{s}}_{\mathbf{1}}$ vary between -0.153 and 1.426 , with a significantly positive value of 0.374 for all firms.

There are two important aspects of-the evidence in Table 1. First, the potential bias in spread estimates due to time variation in expected returns is nontrivial in economic terms. For all firms taken together, the average weekly spread estimate increases from 1.396 to 2.293: an increase of 64 percent. This increase is especially noteworthy because $\hat{\boldsymbol{s}}_{1}-\hat{\boldsymbol{s}}$ provides a lower bound on the bias due to time variation in expected returns (see Property A1). Second, the increase in $\hat{\mathcal{S}}_{1}$ (over $\boldsymbol{s})$ is much larger in weekly, as opposed to daily, data $(1.3 \%$ to 2.293 . versus -0.087 to 0.356 for all firms). Since, by construction, $E_{p t}$ extracts only those components of expected returns that are cross-sectionally correlated, this evidence suggests that daily security returns contain idiosyncratic positively autocorrelated components.

NASDAQ firms. Table 2, panels A and B, shows weekly and daily estimates of the bid-ask spread for NASDAQ firms. Since bid/ask quotes are available for NASDAQ firms, apart from $\hat{\boldsymbol{s}}$ and $\hat{\boldsymbol{s}}_{1}$, we also report $\hat{\boldsymbol{s}}_{2}$. Table 2 also shows more descriptive information about the NASDAQ firms, compared to the information for AMEX/NYSE firms. Apart from sample size and average market value, we also report the average trading volume and average quoted spread, $s_{q}$ for all firms in the sample. The systematic positive relation between trading volume and market value is apparent from the numbers reported. This provides justification for forming portfolios based on size, because they exhibit properties similar to portfolios based on volume.

Perhaps the most important data available for NASDAQ firms are the actual quoted spreads, $s_{q}$ These numbers are calculated using daily inside market quotes: the bids (asks) are the highest (lowest) quotes among all market makers trading the security at the end of each trading day. The quoted spread is reported in percent terms, and is calculated as $\left(\boldsymbol{P}_{\boldsymbol{A}}-\boldsymbol{P}_{\boldsymbol{B}}\right) / \frac{1}{\mathbf{2}}\left(\boldsymbol{P}_{\boldsymbol{A}}+\boldsymbol{P}_{\boldsymbol{B}}\right)$. The numbers for the quoted spread again show substantial variation across firms of different market values. They range from 1.631 to 5.221 for weekly data, and from 1.542 to 4.740 for daily data. The weekly quoted spreads are higher than the daily values only because, given our sampling procedure, more small firms get included in the weekly sample.

Adjustment for time-varying expected returns again leads to an economically and statistically significant increase in spread estimates. In the weekly data, the average estimate of $s$ for all firms is only 0.862 , whereas the average value of $\hat{\boldsymbol{s}}_{\mathbf{1}}$ is 1.953 , which reflects an increase of 
Trble 2

Weekly and dally estimates of the bid-ask epread for NASDAQ stocks sorted by market value, 1983-1987

\begin{tabular}{|c|c|c|c|c|c|c|c|c|c|c|c|c|c|c|c|c|}
\hline Portfolio & $\begin{array}{c}\text { Sample } \\
\text { slze }\end{array}$ & $\begin{array}{l}\text { Average } \\
\text { market } \\
\text { value (in } \\
8 \text { million) }\end{array}$ & $\begin{array}{l}\text { Average. } \\
\text { volume } \\
\text { (in thou- } \\
\text { sands) }\end{array}$ & (\%) & $\stackrel{s}{(\%)}$ & $\begin{array}{l}\text { No. of } \\
\text { nega- } \\
\text { tive } \\
\text { spread } \\
\text { estl- } \\
\text { mates }\end{array}$ & $\stackrel{5}{4}$ & $\begin{array}{l}\text { No. of } \\
\text { nega- } \\
\text { tive } \\
\text { spread } \\
\text { esti- } \\
\text { mates }\end{array}$ & $\frac{\xi}{(\%)}$ & $\begin{array}{l}\text { No. of } \\
\text { nega. } \\
\text { tve } \\
\text { spread } \\
\text { est. } \\
\text { mates }\end{array}$ & $s_{q}-s$ & $\frac{s_{6}-s_{1}}{(\%)}$ & $s_{6}-\xi_{2}^{8}$ & $\begin{array}{l}s_{2}-\xi \\
(\%)\end{array}$ & $\begin{array}{c}f-\xi \\
(x)\end{array}$ & $\begin{array}{c}s_{1}-s \\
(\%)\end{array}$ \\
\hline \multicolumn{17}{|c|}{ A. Weekly estimates } \\
\hline 1 & 1869 & 25.071 & 29.144 & $\begin{array}{c}5.221 \\
(0.416)\end{array}$ & $\begin{array}{c}2.378 \\
(0.334)\end{array}$ & 700 & $\begin{array}{c}3.303 \\
(0.245)\end{array}$ & 579 & $\begin{array}{c}4.564 \\
(0.277)\end{array}$ & 16 & $\begin{array}{c}2.843 \\
(0.570)\end{array}$ & $\begin{array}{c}1.918 \\
(0.253)\end{array}$ & $\begin{array}{c}0.657 \\
(0.187)\end{array}$ & $\begin{array}{c}2.186 \\
(0.442)\end{array}$ & $\begin{array}{c}1.261 \\
(0.146)\end{array}$ & $\begin{array}{c}0.925 \\
(0.362)\end{array}$ \\
\hline 2 & 3067 & 67.910 & 38.656 & $\begin{array}{c}3.129 \\
(0.263)\end{array}$ & $\begin{array}{c}1.509 \\
(0.379)\end{array}$ & 1314 & $\begin{array}{c}2.207 \\
(0.078)\end{array}$ & 1040 & $\begin{array}{c}2.795 \\
(0.172)\end{array}$ & 20 & $\begin{array}{c}2.070 \\
(0.600)\end{array}$ & $\begin{array}{c}0.922 \\
(0.268)\end{array}$ & $\begin{array}{c}0.334 \\
(0.108)\end{array}$ & $\begin{array}{c}1.736 \\
(0.519)\end{array}$ & $\begin{array}{c}0.588 \\
(0.193)\end{array}$ & $\begin{array}{c}1.148 \\
(0.396)\end{array}$ \\
\hline $\begin{array}{l}3 \\
\text { (Largest) }\end{array}$ & 3878 & 384.657 & 85.250 & $\begin{array}{c}1.631 \\
(0.125)\end{array}$ & $\begin{array}{c}-0.026 \\
(0.492)\end{array}$ & 1957 & $\begin{array}{c}1.102 \\
(0.090)\end{array}$ & 1587 & $\begin{array}{c}1.497 \\
(0.081)\end{array}$ & 13 & $\begin{array}{c}1.657 \\
(0.597)\end{array}$ & $\begin{array}{c}0.529 \\
(0.177)\end{array}$ & $\begin{array}{c}0.134 \\
(0.052)\end{array}$ & $\begin{array}{c}1.523 \\
(0.559)\end{array}$ & $\begin{array}{c}0.395 \\
(0.135)\end{array}$ & $\begin{array}{c}1.128 \\
(0.451)\end{array}$ \\
\hline All firms & 8814 & 198.111 & 57.127 & $\begin{array}{c}2.914 \\
(0.292)\end{array}$ & $\begin{array}{c}0.862 \\
(0.297)\end{array}$ & 3971 & $\begin{array}{c}1.953 \\
(0.174)\end{array}$ & 3206 & $\begin{array}{c}2.600 \\
(0.235)\end{array}$ & 49 & $\begin{array}{c}2.052 \\
(0.351)\end{array}$ & $\begin{array}{c}0.961 \\
(0.163)\end{array}$ & $\begin{array}{c}0.315 \\
(0.074)\end{array}$ & $\begin{array}{c}1.738 \\
(0.305)\end{array}$ & $\begin{array}{c}0.647 \\
(0.110)\end{array}$ & $\begin{array}{c}1.091 \\
(0.240)\end{array}$ \\
\hline \multicolumn{17}{|c|}{ B. Dally estimates } \\
\hline $\begin{array}{l}1 \\
\text { (Smallest) }\end{array}$ & 1097 & 28.448 & $\begin{array}{l}36.857 \\
\end{array}$ & $\begin{array}{c}4.740 \\
(0.393)\end{array}$ & $\begin{array}{c}2.164 \\
(0.356)\end{array}$ & 308 & $\begin{array}{c}2.461 \\
(0.417)\end{array}$ & 264 & $\begin{array}{c}4.338 \\
(0.296)\end{array}$ & 1 & $\begin{array}{c}2.576 \\
(0.188)\end{array}$ & $\begin{array}{c}2.279 \\
(0.117)\end{array}$ & $\begin{array}{c}0.402 \\
(0.156)\end{array}$ & $\begin{array}{c}2.174 \\
(0.112)\end{array}$ & $\begin{array}{c}1.877 \\
(0.135)\end{array}$ & $\begin{array}{c}0.297 \\
(0.113)\end{array}$ \\
\hline 2 & $\begin{array}{c}2287 \\
\cdot\end{array}$ & 70.674 & 44.742 & $\begin{array}{c}2.996 \\
(0.246)\end{array}$ & $\begin{array}{r}0.447 \\
(0.167)\end{array}$ & 1045 & $\begin{array}{c}0.965 \\
(0.306)\end{array}$ & 827 & $\begin{array}{c}2.761 \\
(0.175)\end{array}$ & 0 & $\begin{array}{c}2.549 \\
(0.155)\end{array}$ & $\begin{array}{r}2.031 \\
(0.093)\end{array}$ & $\begin{array}{c}0.235 \\
(0.089)\end{array}$ & $\begin{array}{c}2.314 \\
(0.085)\end{array}$ & $\begin{array}{l}1.796 \\
(0.136)\end{array}$ & $\begin{array}{c}0.518 \\
(0.189)\end{array}$ \\
\hline 3 & 3373 & 408.650 & 94.078 & $\begin{array}{c}1.542 \\
(0.114)\end{array}$ & $\begin{array}{c}-0.842 \\
(0.091)\end{array}$ & 2428 & $\begin{array}{c}-0.126 \\
(0.181)\end{array}$ & 1919 & $\begin{array}{c}1.484 \\
(0.079)\end{array}$ & $\mathbf{0}$ & $\begin{array}{c}2.384 \\
(0.190)\end{array}$ & $\begin{array}{c}1.668 \\
(0.087)\end{array}$ & $\begin{array}{c}0.058 \\
(0.045)\end{array}$ & $\begin{array}{c}2.326 \\
(0.153)\end{array}$ & $\begin{array}{c}1.610 \\
(0.108)\end{array}$ & $\begin{array}{c}0.716 \\
(0.253)\end{array}$ \\
\hline All firms & 6757 & 232.531 & 68.090 & $\begin{array}{c}2.553 \\
(0.250)\end{array}$ & $\begin{array}{c}0.082 \\
(0.225)\end{array}$ & 3781 & $\begin{array}{c}0.663 \\
(0.233)\end{array}$ & 3010 & $\begin{array}{c}2.379 \\
(0.212)\end{array}$ & 1 & $\begin{array}{c}2.471 \\
(0.104)\end{array}$ & $\begin{array}{c}1.890 \\
(0.070)\end{array}$ & $\begin{array}{c}0.174 \\
(0.056)\end{array}$ & $\begin{array}{c}2.297 \\
(0.074)\end{array}$ & $\begin{array}{c}1.716 \\
(0.073)\end{array}$ & $\begin{array}{c}0.581 \\
(0.127)\end{array}$ \\
\hline
\end{tabular}

The quoted spread, $s_{\infty}$ is obtained from the NASDAQ tapes. The percent spread is calculated $2 s s_{\text {, }}-200 \sqrt{-C D v_{m}}$ where COv, is the autocovariance of returns in period $t$ for security $x$. Spread estimates $\xi, \xi$, and $\xi$ are based on trensaction returns, $R_{7}$ returns adfusted for time variation in expected returns, $\|_{n}$ and of the difference between returns based on transaction prices and returns calculated using bld-to-bid prices, RD, respectively. The individual.firm quoted spreads and the three spread estimates are each averaged across firms within each porfolio to obtain subperlod averages. Bach reported number is the welghted grand average of the 10 subperiod averages. The last six columns report differences between the quoted spreads and the three spread estimates, and between the three spread estimates themselves. The weighted standard errors, reported in parentheses, are based on the distribution of the subperiod averages. 
over 126 percent. The use of Method 1 leads to a significant, though smaller, increase in spread estimates in daily data, from 0.082 to 0.633 . Therefore, as in the case of AMEX/NYSE stocks, this evidence suggests the presence of security-specific positively autocorrelated components in daily stock returns.

The availability of bid/ask quotes for NASDAQ firms allows us to estimate $s_{2}$ and directly address important aspects of the biases in bid-ask spread measures. First, consistent with the theory, $\hat{\boldsymbol{s}}_{\mathbf{2}}$ is not affected by the differencing interval. The weekly estimates of $s_{2}$ in panel A range between 1.497 and 4.564, with an average value of 2.600 for all firms. Daily estimates of $s_{2}$ are very similar, ranging between 1.484 and 4.338, with an average value for all firms of 2.379 (see panel B). ${ }^{7}$ The minor differences between the weekly and daily estimates are entirely due to the larger number of small firms in the weekly sample. Another important statistic to emphasize is the smaller number of negative estimates of $s_{2}$ (compared to $\hat{\boldsymbol{s}}$ ) only 49 out of a possible 8814 in the weekly sample, and only 1 out of 6757 in the daily data. These numbers stand in sharp contrast to 3971 weekly, and 3781 daily, negative estimates of $s$.

Second, though estimates of $s_{2}$ are significantly larger than $\hat{\boldsymbol{s}}$, and also $\hat{\boldsymbol{s}}_{1}$, they remain less than $s_{q}$. The mean differences between $s_{q}$ and $\hat{\boldsymbol{s}}_{\mathbf{2}}$ are statistically significant in both the weekly and daily samples. However, the economic magnitude of these differences is small: for all firms the difference is 0.315 in the weekly sample, and 0.174 in the daily data. This suggests that although market makers do include an adverse-selection component in their quoted spreads, this component is likely to be small. More detailed analysis of the components of the bid-ask spread is provided in the next subsection.

Third, the downward bias in estimates of the spread based on transaction returns appears to be primarily due to time-varying expected returns. For the weekly sample, the total downward bias in $\hat{\boldsymbol{s}}$ for all films, $\boldsymbol{s}_{\boldsymbol{q}}-\hat{\boldsymbol{s}}$, $\mathrm{j}$ is 2.052 . Of this total bias, the bias due to time variation in expected returns, $\hat{\boldsymbol{s}}_{\mathbf{2}}-\hat{\boldsymbol{s}}$, is 1.738 . Hence, approximately 85 percent of the bias in $\hat{\boldsymbol{s}} \mathrm{i}$ is due to time-varying expected returns (with the proportion varying between 77 and 92 percent for firms within the

\footnotetext{
7 The fact that bid/ask quotes are not measured immediately after the last transaction on a particular day (but at market close) will impart an upward bias in estimates of $s_{2}$. This follows because the serial covariance of measured $\mathbf{R D}_{n}$ will not be given by Equation (12), but will be
}

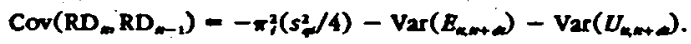

The last two components in the above expression measure the variance of the expected return and unexpected return components over the interval between the last transaction and market close. These components lead to an upward bias in $\boldsymbol{\xi}_{\mathbf{2}}$ However, in Section 4.3 we provide some evidence that this upward bias is small. 
three portfolios). Similar conclusions can be arrived at based on the daily evidence. For all firms in the sample, about 93 percent of the downward bias in 5 is due to time variation in expected returns. This proportion varies between 84 and 97 percent for firms within the three portfolios. ${ }^{8}$

Finally, if bid/ask quotes are not available (as in the case of NYSE/ AMEX stocks), and therefore we are interested in estimates of the spread, it is always better to use Method 1. Adjustment for time-varying expected returns leads to estimates of the bid-ask spread that are significantly less biased than $\hat{s}$, especially in the weekly sample.

\subsection{Components of the bid-ask spread}

Tables 3 and 4 show weekly and daily estimates of regression (15a)(15c) for NASDAQ stocks in panels A-C. Each of these regressions is estimated cross-sectionally for all firms within a particular portfolio, and for all firms in the sample. All three regressions are estimated for each subperiod. The reported parameter estimates are weighted averages of the subperiod estimates, with weighted standard errors based on the distribution of the 10 subperiod values in parentheses.

Since regression (15c) is well-specified, and the estimators $\hat{\boldsymbol{\alpha}}_{2 \boldsymbol{t}}$ and $\hat{\boldsymbol{\beta}}_{\mathbf{2}}$ are unbiased and efficient, we first analyze the estimates reported in panel C of Tables 3 and 4. Estimates of $\boldsymbol{\alpha}_{\mathbf{2}}$ and $\boldsymbol{\beta}_{\boldsymbol{2} \boldsymbol{\varepsilon}}$ can be used as benchmarks to gauge the potential biases in estimates of the parameters of regressions (15a) and (15b). Both for the weekly and daily samples, estimates of $\boldsymbol{\alpha}_{\mathbf{2}}$ are all positive and usually less than 2.0 standard errors from zero. The only notable exception is for portfolio 3. However, even for this portfolio, the economic magnitudes of $\hat{\boldsymbol{\alpha}}_{\mathbf{2}}$ (0.131 and 0.102) are trivial compared to the levels of the quoted spreads, and the biases in $\hat{\boldsymbol{\alpha}}$ (see panel A). The consistently positive estimates of a, show that the $\hat{\boldsymbol{s}}_{\mathbf{2}}{ }^{\prime}$ s are. upward biased because the measured $\mathbf{R D}_{\boldsymbol{u}}$ 's contain innovations in expected and unexpected returns over the interval between the last transaction and market close (see note 7). However, the small magnitudes of the $\hat{\boldsymbol{\alpha}}_{2}$ 's also suggest that this bias is small.

The behavior of the estimates of $\boldsymbol{\beta}_{\mathbf{2}}$, in the weekly and daily samples, has some important implications. First, consistent with the theory, the measurement interval has virtually no impact on estimates of the components of the spread. With the sole exception of portfolio 3, we cannot reject the hypothesis that the daily and weekly $\boldsymbol{\beta}_{\mathbf{2}}$ 's are identical. Second, estimates of $\boldsymbol{\beta}_{\mathbf{2}}$, which measure $\pi$, are very similar across

\footnotetext{
- These estimates provide a lower bound on the bias in 3 due to time-varying expected returns because, in the presence of adverse selection, $\xi_{2}-\xi$ will understate the true bias. Whith adverse selection, $s_{2}=\pi s_{q}<\sqrt{\pi} s_{r}$ and the "true" downward blas, $\sqrt{\pi s_{q}}-\xi$, will be greater than $\xi_{2}-\xi-$ $\pi s_{4}-1$
} 
Table 3

Weekly regressions of estlmated spreads on quoted spreads for NASDAQ stocks sorted by market ralue, 1983-1987

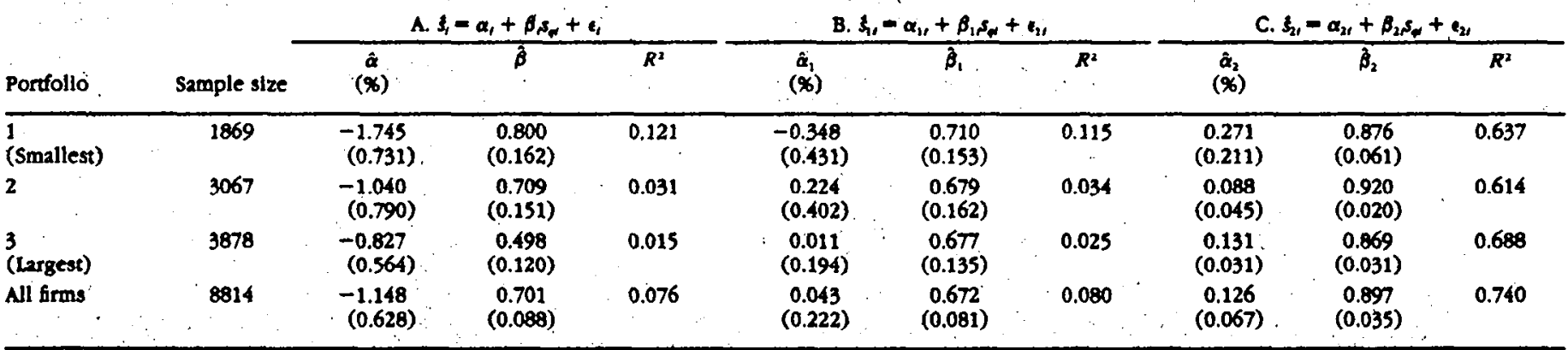

The three spread estimates $\xi_{1} \xi_{h}$, and $\xi_{i}$ are calculated for each securlty for each subperiod using $\xi_{j}-200 \sqrt{-C D v_{p}} j-1,2,3$, where Cov, is the autocovariance of transaction returns, $R_{m}$ returns adjusted for time variation in expected returns, $\eta_{n}$ and of the difference between retums based on transaction prices and returns calculated using bid-to-bid prices, $R D$, respectively. The quoted spread, $s$, for each security for each subperiod is obtained from the $N A S D A O$ tapes. The regression parameters are estlmated cross-sectionally for all firms within a particulas porfollo (and for all firms in our sample) during cach subpertod. Each reported parameter estimate is the weighted average of the subperiod values. The numbers in parentheses below the averages are welghted standard errors based on the distribution of the subperiod estimates. 
Table 4

Dally regreseions of estimated spreads on quoted spreads for NASDAQ stocks sorted by market value, 1983-1987

\begin{tabular}{|c|c|c|c|c|c|c|c|c|c|c|}
\hline \multirow[b]{2}{*}{ Portfolto } & \multirow[b]{2}{*}{ Sample size } & \multicolumn{3}{|c|}{ A. $s_{1}=a_{1}+\beta s_{\alpha}+c_{1}$} & \multicolumn{3}{|c|}{ B. $s_{1},=\alpha_{1}+\beta_{1} s_{\psi}+c_{11}$} & \multicolumn{3}{|c|}{ C. $s_{11}=\alpha_{21}+\beta_{22} s_{4}+\varepsilon_{21}$} \\
\hline & & $\begin{array}{c}\dot{\alpha} \\
(\%)\end{array}$ & $\hat{\beta}$ & $R^{2}$ & $\begin{array}{c}\dot{a}_{1} \\
\left(\alpha_{)}\right.\end{array}$ & $\hat{\beta}_{1}$ & $R^{2}$ & $\stackrel{\dot{w}_{2}}{(\%)}$ & $\overline{\boldsymbol{\beta}}_{2}$ & $R^{2}$ \\
\hline $\begin{array}{l}1 \\
\text { (Smallest) }\end{array}$ & 1097 & $\begin{array}{l}-2.111 \\
\cdot(0.272)\end{array}$ & $\begin{array}{c}0.923 \\
(0.071)\end{array}$ & 0.458 & $\begin{array}{c}-1.667 \\
(0.221)\end{array}$ & $\begin{array}{c}0.897 \\
(0.066)\end{array}$ & 0.465 & $\begin{array}{c}0.315 \\
(0.210)\end{array}$ & $\begin{array}{c}0.878 \\
(0.068)\end{array}$ & 0.810 \\
\hline 2 & 2287 & $\begin{array}{c}-2.582 \\
(0.218)\end{array}$ & $\begin{array}{c}1.040 \\
(0.091)\end{array}$ & 0.301 & $\begin{array}{c}-1.818 \\
(0.215)\end{array}$ & $\begin{array}{c}0.966 \\
(0.089)\end{array}$ & 0.294 & $\begin{array}{c}0.080 \\
(0.039)\end{array}$ & $\begin{array}{c}0.948 \\
(0.013)\end{array}$ & 0.873 \\
\hline $\begin{array}{l}3 \\
\text { (Largest) }\end{array}$ & 3373 & $\begin{array}{c}-2.200 \\
(0.168)\end{array}$ & $\begin{array}{c}0.913 \\
(0.049)\end{array}$ & $\begin{array}{c}0.175 \\
.\end{array}$ & $\begin{array}{c}-1.553 \\
(0.101)\end{array}$ & $\begin{array}{c}0.957 \\
(0.048)\end{array}$ & 0.194 & $\begin{array}{c}0.102 \\
(0.015)\end{array}$ & $\begin{array}{c}0.933 \\
(0.012)\end{array}$ & 0.895 \\
\hline All firms & 6757 & $\begin{array}{c}-2.300 \\
(0.189)\end{array}$ & $=\begin{array}{c}0.964 \\
(0.050)\end{array}$ & $\begin{array}{l}0.444 \\
\cdots\end{array}$ & $\begin{array}{r}-1.571 \\
(0.112)\end{array}$ & $\begin{array}{c}0.911 \\
(0.038)\end{array}$ & 0.437 & $\begin{array}{c}0.144 \\
(0.068)\end{array}$ & $\begin{array}{c}0.915 \\
(0.037)\end{array}$ & 0.895 \\
\hline
\end{tabular}

The three spread estimates $s, s_{1}$, and $\xi_{2}$ are calculated for each security for each subperiod using $s_{\mu}-200 \sqrt{-C \delta v_{p s}} f=1,2,3$, where Cov, is the autocovariance of transaction retums, $R_{n}$ returns adjusted for time variation in expected returns, $\eta_{n}$ and of the difference between returns based on transaction prices and returns calculated using bid-to.bid prices, $\mathrm{RD}_{n}$ respectively. The quoted spread, $s_{-\infty}$ for each securlty for each subperiod is obtained from the NASDAQ tapes. The regresslon parameters are estimated cross-sectionally for all firms within a particular portfolio (and for all firms in our sample) during each subperiod. Each reported parameter estimate is the welghted average of the subpertod values. The numbers in parentheses below the averages are weighted standard errors based on the distribution of the subperlod estimates. 
firms of different market value. For example, in the weekly data the hypothesis that the $\beta_{2}$ 's for firms within each portfolio are equal to 0.897 (the average value of $\beta_{2}$ for all firms) cannot be rejected at conventional significance levels. Similar conclusions can be arrived at based on the daily evidence, with the sole exception of portfolio 2. This similarity in estimates of $\beta_{2}$ across firms of -different market value is consistent with the findings of Stoll (1989), which show that, although the quoted spread varies considerably across stocks, the components of the spread appear to be a fixed proportion of the quoted spreads.

The most important implication of the evidence in panel $\mathrm{C}$, however, is related to the magnitudes of the estimates of $\beta_{2}$ In both daily and weekly samples, we can reject the hypothesis that $\beta_{2}$ 's for all firms are equal to 1.0, which suggests that quoted spreads do contain an adverse-selection component. However, the magnitudes of estimates of $\beta_{2}$, which are 0.897 and 0.915 for all firms in the weekly and daily samples, indicate that the adverse-selection component is a much smaller proportion of the spread than documented in earlier studies. Based on the estimates for all firms, the proportion of the spread due to adverse selection, $\mathbf{1}-\hat{\boldsymbol{\beta}}_{\mathbf{2}}$, ranges between 8 and 13 percent. These estimates are less than one third the magnitude of 43 percent reported by Stoll (1989). ${ }^{9}$

Finally, regression $(15 \mathrm{c})$ appears to be well-specified: the average $R^{2} s$ in weekly data range between 60 and 75 percent, and between 80 and 90 percent in the daily data. The efficiency of $\hat{\boldsymbol{\alpha}}_{\mathbf{2}}$ and $\hat{\boldsymbol{\beta}}_{\mathbf{2}}$ reflected in their low standard errors. Hence, not only is $\beta_{2}$ an unbiased estimator of $\pi$, but it also provides precise (and hence reliable) estimates.

In contrast, parameter estimates. of regression (15a) in panel A of Tables 3 and 4 demonstrate the unreliability of inferences based on point estimates of regressions using transaction-return-based spread measures. First, the high sampling variance of 3 leads to low $R^{2}{ }^{\prime} s$,

\footnotetext{
As a result of the fact that $R D_{i t}$ contains innovations in expected and unexpected returns over the interval between the last transaction and market close, estimates of $\boldsymbol{\beta}_{\mathbf{2}}$ may be upward biased. This can occur because the variances of these two components arc likely to be cross-sectionally positively correlated with the spread [see regression (15a)]. Also, there may be potential upward bias in $\hat{\boldsymbol{\beta}}_{2}$ because we sample stocks that trade every day (week), as opposed to all stocks that are listed on the exchange each day. However, this bias will be large only if quantity traded is not completely inelastic with respect to changes in the spread and most of the variation In the spread is due to changes in the adverse-selection component. Unfortunately, it is not possible to empirically evaluate the extent of these biases. However, these biases are likely to be attenuated by a downward bias in $\hat{\boldsymbol{\beta}}_{\mathbf{2}}$. Recall that we assume that end-of-day buy and sell orders are equally likely, and serially Independent. There is some evidence, however, that the last trades of a day tend to occur more frequently at the ask price [see, e.g., Harris (1989)]. Unfortunately, we cannot estimate the ex ante probability of buy/sell orders for our sample because the bid/ask quotes are typically measured after the last trade. It can be shown, however, that if the ex ante probabilities of buy and sell orders are not equal, then our estimates of the slope coefficients in regressions (15a)-(15c) will be downward biased [see, e.g., Chol. Salandra. and Shastri (1988).
} 
especially when compared to the $R^{2}{ }^{\prime} s$ of regression (15c). The differences in the $R^{2}$ 's are, as stated in Property B3, much larger in weekly data, and much greater for larger firms. For example, the average $R^{2}$ for all firms in the weekly sample for regression (15a) is only 7.6 percent versus an average $R^{2}$ of 74 percent for regression $(15 \mathrm{c})$, and for large firms (portfolio 3) the numbers are 1.5 percent versus 68.8 percent. The differences in $R^{2}$ 's, though smaller, are still substantial in daily data: the comparable numbers for all firms are 44.4 percent versus 89.5 percent. These differences, in turn, are reflected in the much higher standard errors of $\hat{\boldsymbol{\alpha}}$ and $\hat{\boldsymbol{\beta}}_{1}$ compared to the standard errors of $\hat{\boldsymbol{\alpha}}_{\mathbf{2}}$ and $\hat{\boldsymbol{\beta}}_{\mathbf{2}}$. For example, the standard error of $\hat{\boldsymbol{\alpha}}$ for all firms in the weekly sample is 0.628 as opposed to only 0.067 for $\hat{\boldsymbol{\alpha}}_{\mathbf{2}}$. Moreover, the standard errors of the estimators of the slope coefficients are 0.088 versus 0.035 . Similar differences, though smaller in magnitude, exist in the daily estimates_ (see panels $\mathrm{A}$ and $\mathrm{C}$ of Table 4). The high standard errors of $\hat{\boldsymbol{\alpha}}$ and $\hat{\boldsymbol{\beta}} \mathbf{1}$ reflect their imprecision, and caution against using point estimates to draw inferences, especially in weekly data and for larger firms.

Second, the downward bias in $\hat{\boldsymbol{s}} \boldsymbol{c}$ due to time-varying expected returns is reflected in the large negative estimates of a: the average value of \&for all firms is -1.148 in the weekly and -2.300 in the daily samples. These estimates are large in magnitude compared to the respective levels of the quoted spreads of 2.914 and 2.553. However, because of the large standard errors, the estimates of a are often not significantly different from zero in the weekly data.

Third, and perhaps most importantly, $\hat{\boldsymbol{\beta}}$, which measures $\sqrt{\boldsymbol{\pi}}$, is biased. This bias is reflected in two important ways: (i) There is a substantial interval effect on $\hat{\boldsymbol{\beta}}$. For all firms in our sample, the weekly estimate of $\beta$ is 0.701 versus a value of 0.964 in the daily data. Furthermore, even with the high standard errors, these estimates are significantly different from each other. Consequently, based on the weekly and daily data, we draw very different conclusions about even the existence of adverse selection in securities markets, The weekly data suggest that, for all firms in our sample, approximately 50 percent, $\mathbf{1}-\hat{\boldsymbol{\beta}}_{\mathbf{2}}$,of the quoted spread is due to the adverse-selection component, whereas the daily data indicate virtually no adverse selection in the market. ${ }^{10}$ The daily estimate of $\beta$ is not statistically different from 1.0 even if we use lower standard errors based on estimates of regression $(15 \mathrm{c})$. These substantially divergent estimates of the rel-

\footnotetext{
${ }^{10}$ Estimates of the components of the spread based on $\hat{\boldsymbol{\beta}}$ and $\hat{\boldsymbol{\beta}}_{1}$ ate approximate because they measure $\sqrt{\boldsymbol{\pi}}$, and we square the estimates to obtain values of $\pi$. And squared values of $\hat{\boldsymbol{\beta}}$ and $\hat{\boldsymbol{\beta}}$, will not be unbiased estimates of $\pi$. Nevertheless, these values provide an idea of the markedly different estimates of the components of the spread obtained from daily and weekly serial covariances of transaction returns.
} 
ative importance of the adverse-selection component stand in stark contrast to the proportions of 10.3 and 8.5 percent obtained from weekly and daily estimates of $\boldsymbol{\beta}_{\mathbf{2}}$. (ii) Estimates of $\beta$ also vary substantially across firms in the three market value portfolios. They range between 0.498 and 0.800 in the weekly sample, and between 0.913 and 1.040 in daily data.

Estimates of regression (15b) are reported in panel B of Tables 3 and 4. Unfortunately, since Method 1 cannot fully correct for timevarying expected returns, estimates of $\boldsymbol{\beta}_{\mathbf{1}}$ remain biased. Both daily and weekly estimates are downward biased, although there is a marked improvement in the dally estimates. For example, for all firms in our sample, the weekly estimate of the proportion of the bid-ask spread due to adverse selection is 45.2 percent, whereas the corresponding daily estimate is 17 percent. Note that these estimates are again approximate because they are calculated $\mathbf{1}-\hat{\boldsymbol{\beta}}^{\mathbf{2}}$.

One possible explanation for the downward bias in $\hat{\boldsymbol{\beta}}$ and $\hat{\boldsymbol{\beta}}_{\mathbf{1}}$ is that the autocovariance generated by time-varying expected returns is positively correlated with $s_{q i}$. The positive (cross-sectional) correlation between $\operatorname{Cosv}\left(\boldsymbol{E}_{v \mathfrak{s}} \boldsymbol{E}_{\boldsymbol{t} t-1}\right)$ and $s_{q i}$ is suggested by the fact that smallerfirms exhibit a higher degree of variation in expected returns [see Conrad and Kaul (1988) and Lo and MacKinlay (1988)], and they also tend to have larger quoted spreads. And since $\operatorname{Côv}\left(E_{t r} E_{t r-1}\right)$ enters with a negative sign in the formulas for $\hat{\boldsymbol{s}}$ and $\hat{\boldsymbol{s}}_{\mathbf{1}}$, both $\hat{\boldsymbol{\beta}}$ and $\hat{\boldsymbol{\beta}}_{\mathbf{1}}$ are downward biased. In Section 5.5, we provide some evidence in favor of this explanation. ${ }^{11}$

The analysis of the estimates of regressions (15a)-(15c) underline the importance of utilizing the information contained in both transaction prices and bid/ask quotes, while estimating the components of the spread. Specifically, Method 2 provides unbiased and efficient estimators of the spread components. If bid/ask quotes are not available, using Method 1 to adjust transaction returns for time-varying expected returns usually does not yield unbiased estimates of the components of the spread. However, this method provides more realistic estimates of the level of the spread as shown in Section 4.2. The comparative magnitudes of $\hat{\boldsymbol{\alpha}}$ and $\hat{\boldsymbol{\alpha}}_{\mathbf{1}}$ in Tables 3 and 4 also exhibit the marked reduction in the bias due to time-varying expected returns when Method 1 is used to extract $\boldsymbol{E}_{\boldsymbol{f f}}$ 's from transaction returns. ${ }^{12}$

\footnotetext{
${ }^{11}$ This, however, cannot be the complete explanation for our results. Although it is consistent with the downward bias in $\hat{\boldsymbol{\beta}}_{1}$ In the weekly and daily data, and also with the downward bias in weekly $\hat{\boldsymbol{\beta}}$ 's of regression (15a). It cannot explain the upward bias in daily estimates of $\beta$.

${ }^{12}$ However, estimates of $\dot{\boldsymbol{x}}$ and $\boldsymbol{\alpha}_{\mathbf{1}}$ in panels A and B (Tables 3 and 4) should be interpreted with caution. Since $\hat{\boldsymbol{\beta}}$ and $\hat{\boldsymbol{\beta}}_{1}$; are downward biased, there is a resulting upward bias (i.e., toward zero) in $\hat{\boldsymbol{\alpha}}$ and $\hat{\boldsymbol{\alpha}}_{1}$. : For example, weekly estimates of $\boldsymbol{\alpha}_{\mathbf{1}}$ are statistically indistinguishable from zero, which would suggest that Method 1 completely eliminates the downward bias in $\$$ due to time-varying expected returns. However, this occurs primarily because $\hat{\boldsymbol{\beta}}_{\mathbf{1}}$ is substantially downward biased.
} 
Trade size and the spread. The estimation of the components of the spread has been carried out under the assumption that all trades are of unit size or, equivalently, that the spread is independent of trade size. If this assumption is valid, then the adverse-selection component will be 8 to 13 percent of the spread for all quantities of trade. However, the spread maybe a function of order size. For example, Easley and O'Hara (1987), Glosten (1989), and Kyle (1985) present models that suggest that the adverse-selection component should increase with order size; Likewise, inventory models of the spread would suggest that order-processing costs also increase with trade size.

If the dollar spreads due to both order-processing costs and adverse selection increase with order size, but they remain constant proportions of the spread, then our estimate of the components based on $s_{2}$ will be valid for all trade sizes. If, however, only the adverse-selection component of the spread varies with trade size [see, e.g., Glosten and Harris (1988)], then our estimate of the adverse-selection spread based on $s_{2}$ will measure the importance of this component for small trades (and hence will provide a lower bound estimate for large informationbased trades). This follows because $s_{2}$ is based on $\mathrm{RD}_{t}$, which, in turn, is the difference between the transaction and bid returns. The autocovariance of this difference reflects the change in expectations associated with only that part of the last order for which the market maker is committed to trade at his quote. This leaves us with an estimate of $\pi$ for small trades only.

On the other hand, since $s_{1}$ is based on transaction returns (and not differences in returns), $\hat{\boldsymbol{\beta}}_{\mathbf{1}}$ can be used to obtain an estimate of the quantity-contingent adverse-selection component. Unfortunately, however, because of the bias and imprecision of $\hat{\boldsymbol{\beta}}_{\mathbf{2}}$, and the widely varying weekly and daily estimates of the adverse-selection component (45 percent versus 17 percent), we cannot draw reliable inferences about the quantity-contingent adverse-selection component of the spread.

\section{Some Sensitivity Tests}

In this section, we provide some discussion of the sensitivity of our results and conclusions to changes in the assumptions underlying our model and estimation techniques.

\subsection{The regression specification}

Our analysis of the components of the bid-ask spread is based on regressing $\hat{\boldsymbol{s}}_{\mathbf{1}}, \hat{\boldsymbol{s}}_{\mathbf{i n}}$ and $\hat{\boldsymbol{s}}_{\mathbf{2}}$ on the quoted spread $s_{q i}$. However, mathematically all spread measures are derived from covariances of returns 
which are directly related to the square of the spread [see Equation (4)]. We estimate regressions (15a)-(15c) instead because the intercepts of these regressions have an appealing intuitive interpretation: they measure the bias in spread estimators due to time-varying expected returns and/or partial price adjustments. Both academicians and practitioners are presumably interested in the level of the spread, rather than squared spreads.

For completeness, however, we also estimate regressions (15a)$(1 \%)$ in their squared form, that is,

$$
\begin{aligned}
& \hat{s}_{t t}^{2}=\alpha_{t}^{\prime}+\beta_{t}^{\prime} s_{q t}^{2}+\epsilon_{t t}^{\prime}, \\
& \hat{s}_{1 t t}^{2}=\alpha_{1 t}^{\prime}+\beta_{1}^{\prime} s_{q t}^{2}+\epsilon_{1 t t}^{\prime}, \\
& \hat{s}_{2 t t}^{2}=\alpha_{2 t}^{\prime}+\beta_{2 t}^{\prime} s_{q t}^{2}+\epsilon_{2 t t}^{\prime} .
\end{aligned}
$$

Note that $\boldsymbol{\beta}_{\boldsymbol{i}}^{\prime}$ and $\boldsymbol{\beta}_{\mathbf{1}}^{\prime}$ : measure the proportion of the spread due to order-processing costs, $\boldsymbol{\pi}_{\boldsymbol{n}}$ whereas $\boldsymbol{\beta}_{\mathbf{2}}^{\prime}$ measures $\boldsymbol{\pi}_{\boldsymbol{1}}^{2}$. The evidence, not reported, provides further support for the use of $\hat{\boldsymbol{s}}_{\mathbf{2} \boldsymbol{t}}$ as opposed to $\hat{\boldsymbol{s}}_{\boldsymbol{t}}$ or $\hat{\boldsymbol{S}}_{\mathbf{1}}$ in estimating the spread components. The square roots of the estimates of $\boldsymbol{\beta}_{\mathbf{2}}^{\prime}$ are very similar to the estimates of $\boldsymbol{\beta}_{\mathbf{2} \boldsymbol{n}}$ both in the daily and weekly regressions. For example, for all firms in our sample, the daily and weekly values of $\sqrt{\hat{\boldsymbol{\beta}}_{2}^{\prime}}$ re 0.925 and 0.933 , respectively. These estimates are statistically indistinguishable from the corresponding estimates of $\boldsymbol{\beta}_{\mathbf{2}}$ of 0.915 and 0.897 reported in Tables 3 and 4. However, estimates of the parameters of regression (15c') are much more imprecise than the estimates of regression (15c). Consequently, we cannot reject the hypothesis that there is no adverse selection in securities' markets. Hence, although the point estimates of regressions $(15 \mathrm{c})$ and $\left(15 \mathrm{c}^{\prime}\right)$ are almost identical, it may be more appropriate to estimate regression (15c) because of the higher precision of its estimates.

Estimates of regressions (15a') and (15b') again provide qualitatively similar results to those of regressions (15a) and (15b). The implied estimates of $\boldsymbol{\pi}_{\boldsymbol{t}}$ are higher in both daily and weekly data, but they remain unreliable because the weekly and daily data again provide very different estimates of the spread components.

\subsection{Measurement of transaction prices and bid/ask quotes}

Recall that our second spread estimator $\hat{\boldsymbol{s}}_{\boldsymbol{2}}$ is based on the difference between transaction and bid returns, where the bid prices are assumed to be measured subsequent to each transaction. However, if some bid prices are measured simultaneously, the definition of bid returns and, consequently, of our spread estimator $\hat{\boldsymbol{s}}_{2 \mathrm{t}} \mathrm{will}$ be altered. Let $I_{i t}$ be 
equal to 0 or 1 as the bid quote is subsequent or simultaneous to transaction $t$, where $E\left(I_{i t}\right)=d$. Then $\hat{\boldsymbol{s}}_{\mathbf{2}}$, can be modified to ${ }^{13}$

$$
\hat{s}_{21}=\sqrt{d+\pi_{i}^{2}(1-d)} s_{q t}
$$

Note that if all quotes are reported subsequent to each transaction $t$, then $d=0$ and our original measure of the spread in Equation (11) obtains (i.e., $\hat{\boldsymbol{s}}_{2 t}=\boldsymbol{\pi} \boldsymbol{s}_{q \tau}$ ). On the other hand, if all bid prices are measured simultaneously, $d=1$ and $\hat{\boldsymbol{s}}_{\mathbf{2 t}}=\boldsymbol{s}_{\boldsymbol{q} \boldsymbol{t}}$. Under these circumstances, no information about the components of the spread can be obtained by estimating regressions (15a) or (15a').

Since all bid/ask quotes reported in the NASDAQ data files are daily closing prices, while the transaction prices relate to the last trade of the day, the two sets of prices can be measured simultaneously only when market-at-close orders occur. More importantly, such orders have to be fairly frequent for our estimates of the components of the spread to change substantially. From Equation (16) it can be seen that if market-at-close orders occur, the slope coefficient of regression (15a), $\boldsymbol{\beta}_{2 n}$ will not measure $\boldsymbol{x}_{n}$ but will be a measure of $\sqrt{\boldsymbol{d}+\boldsymbol{\pi}_{\boldsymbol{i}}^{2}(\mathbf{1}-\boldsymbol{d})}$.In Table 5, we present daily and weekly estimates of $\pi$ for different values of $d$, using the point estimates of $\beta_{2}$ for all firms in our sample (0.915 and 0.897 , respectively). Specially, $\dot{\boldsymbol{\pi}}$ is calculated as

$$
\hat{\pi}=\sqrt{\frac{\hat{\beta}_{2}^{2}-d}{1-d}}
$$

Table 5, column 2, shows that even if $d=0.50$ (i.e., as much as 50 percent of all last trades on the NASDAQ occur at market close), the daily estimate of $\boldsymbol{\pi}$ remains as high as 0.82 . Also, note that Stoll's (1989) estimate of 43 percent for the adverse-selection component would require more than 75 percent of all last trades to be marketat-close orders. Similar conclusions can be arrived at using the weekly estimate of $\beta_{2}$ to compute $\hat{\boldsymbol{x}}$ 's (see column 3 ).

As a result of lack of intraday time-stamped data, we cannot estimate $d$ for our sample of NASDAQ stocks. However, there is evidence to suggest that market-at-close orders are not frequent on the NASDAQ. Harris (1989) notes that such orders are quite uncommon on the NYSE. During his 1981-1983 sample period, these orders were placed only for large stocks, and on option expiration days. Fortunately, we

${ }^{13}$ This altered expression can be derived from $R D_{i t}$, which can now be witten as

$$
\mathrm{RD}_{n}=\pi(s / 2)\left[Q_{n}-Q_{n-1}\right]+(1-\pi)(s / 2)\left(I_{s} Q_{n}-I_{n-1} Q_{n-1}\right]
$$


Table 5

Sensitivity of estimates of the components of the bld-ask opread to almultaneous measurement of transaction prices and bid quotes for all NASDAQ atocks, 1983-1987

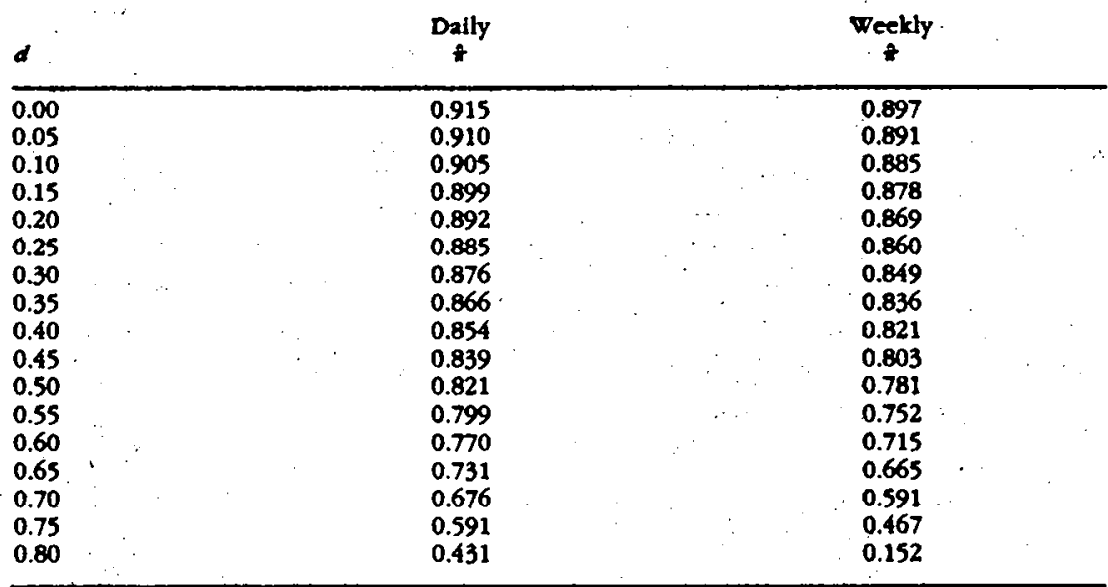

The dally and weekty f's are calculated using Equation (17) and estimates of $\boldsymbol{A}_{2}$ from regression (15c) for all firms in our sample [1.e., $\hat{f}-\sqrt{\left(\hat{\beta}_{2}^{2}-\phi\right) /(1-\phi)}$, where $\hat{\beta}_{2}=0.915$ in the daily data and -0.897 in the weekly data).

were also able to obtain the frequency of market-at-close orders for a sample of AMEX firms. Our sample of NASDAQ stocks is more comparable to AMEX firms based on size and trading frequency [see Keim (1989)] and, consequently, the "true" d's are likely to be similar for the two exchanges.

Based on a random sample of 200 AMEX firms that traded between January 1988 and December 1988, the proportion of all (daily) last trades that are market-at-close orders is only 12.7 percent (i.e., $d=$ $0.127) .{ }^{14} \mathrm{~A} d$ of 0.127 , in turn, implies a daily estimate of $\pi$ of 0.902 (and a weekly estimate of 0881). These estimates are virtually identical to estimates of $\boldsymbol{\beta}_{\mathbf{2}}$ reported in the article $(0.915$ and 0.897 , respectively). The adverse-selection component, therefore, is likely to be a relatively small part of the bid-ask spread. For all firms in our sample, a maximum of 12 percent of the spread can be due to adverse selection. And even if market-at-close orders constitute as much as 50 percent of all last daily trades, the adverse-selection component will only be 18 to 20 percent of the spread.

\subsection{Price discreteness and nonsynchronous trading}

Price discreteness and nonsynchronous trading can also lead to negative autocorrelation in security returns, and thus bias spread esti-

\footnotetext{
${ }^{4}$ We are extremely grateful to Charles Lee for taking the time to calculate this estimate for us based on his time-stamped intraday data.
} 
mates based on return autocovariances. However, we find some evidence which suggests that the effects of these two sources of negative autocovariance are likely to be much smaller than the negative autocorrelation generated by the order-processing cost component of the spread. Note that $\boldsymbol{R}_{\boldsymbol{B} \boldsymbol{B} \boldsymbol{t}}$ does not contain the bid-ask effect but, like the transaction returns, $\boldsymbol{R}_{\boldsymbol{i} \boldsymbol{m}}$ they do contain measurement errors due to price discreteness. However, we find that although daily autocorrelation of $\boldsymbol{R}_{\boldsymbol{m} \boldsymbol{x}}$ 's is significantly negative, the autocorrelation of ' $\boldsymbol{R}_{\boldsymbol{A B t}}$ 's is significantly positive. In fact, for all firms in our sample, the daily firstorder autocorrelation of $\boldsymbol{R}_{\boldsymbol{A} \boldsymbol{B}}$ i is 0.14 ! The negative autocorrelation of transaction returns, and the positive autocorrelation of bid returns, suggests that the bid-ask effect, and not price discreteness (or nonsynchronous trading), is the predominant source of measurement errors in daily and weekly returns. Given this evidence, and the fact that the discreteness effect is uniform in cross section [see Glosten and Harris (1988)], we do not employ the (much more) costly estimation procedure necessary to model discreteness.

\subsection{Importance of inventory holding costs}

In this article, we have assumed that the quoted spread does not contain an inventory cost component arising from the risk borne by the market maker. We also conduct some tests to verily the validity of this assumption. As shown by Stoll (1989), the inventory cost component should lead to negative autocorrelation in returns based on bid (or ask) quotes. Stoll finds weak evidence for an inventory cost component based on daily data for two months. However, we find no evidence for the existence of an inventory cost component. In fact, the-first-order autocorrelation in bid-to-bid returns is positive in both the daily and weekly samples. The difference between our estimates and the evidence in Stoll (1989) may largely be due to the substantial differences in sample sizes: five years versus two months.

\subsection{Expected returns of portfolios versus individual securities} In Section 4, we show that Method 1 should be used to calculate spread estimates (i.e.,. use $s_{1}$ instead of $s$ ) if bid/ask quotes are not available. Method 1 uses portfolio expected returns, $E_{p t}$ to extract the expected returns of individual securities, $E_{i}$, since the latter are not observable [see regression (8)]. In order to ensure that $E_{P t}$ does not induce spurious negative serial covariance in the residuals of regression (8), we assume that the autoregressive parameters of all securities within a particular portfolio are equal (i.e., $\boldsymbol{\phi}_{\boldsymbol{\omega}}=\boldsymbol{\phi}_{\boldsymbol{\theta}}, \forall \boldsymbol{i}$ ). Since this assumption might be restrictive, we conduct some tests to evaluate its effects on our results.

From the definition of bid returns in Equation (10), it can be seen 
that the serial covariance of $\boldsymbol{R}_{\boldsymbol{b B t}}$ will solely reflect the effects of timevarying expected returns:

$$
\operatorname{Cov}\left(R_{t B s} R_{t B z-1}\right)=\operatorname{Cov}\left(E_{t n} E_{t t-1}\right) \text {. }
$$

To gauge whether use of $E_{p t}$ induces spurious negative autocorrelation in $\boldsymbol{\eta}_{\boldsymbol{i}}$ 's _[the residuals of regression (8)] by extracting more than $\operatorname{Cov}\left(\boldsymbol{E}_{\boldsymbol{t}} \boldsymbol{E}_{t-1-1}\right)$, we estimate a new set of daily spreads by sub-

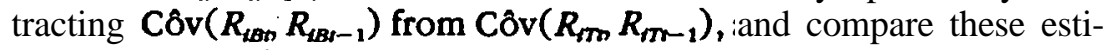
mates with the $\hat{\boldsymbol{s}}_{\mathbf{1}}$ 's. For firms in each portfolio the alternative spread estimates are significantly larger than the $\hat{\boldsymbol{s}}_{1}$ 's. The new average estimates of the spread for firms in portfolios 1,2, and 3 are 3.506, 2.098; and 1.023 percent, which are much larger than the $\hat{\boldsymbol{s}}_{1}^{\prime} \mathbf{s}$ of $2.461,0.965$, and -0.126 percent, respectively. ${ }^{15} \mathrm{We}$ also calculate the number of observations for which $\operatorname{Cov}\left(\boldsymbol{R}_{\mathbf{A B t}} \boldsymbol{R}_{\mathbf{B g}-\mathbf{1}}\right)$ is less than the serial covariance of the fitted values of regression (8)-that is, $\operatorname{Cov}\left(\hat{\boldsymbol{\gamma}}_{0,}+\right.$

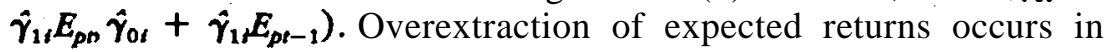
only 10 percent of the observations: 702 times out of entire sample of 6757 observations. We reestimate $\boldsymbol{s}_{2,}$ 's and regressions (15b) and (15b') by excluding the 702 observations for which overextraction occurs. Dropping the 10 percent observations does not significantly alter any of our results or conclusions. Hence, our assumption that the autoregressive parameters of all securities within a particular sizebased portfolio are equal does not appear to be unrealistic.

The availability of bid/ask quotes for individual securities also allows us to test the conjecture that $\hat{\boldsymbol{\beta}}_{\mathbf{s}}$ and $\hat{\boldsymbol{\beta}}_{\mathbf{1}}$ in regressions (15a) and (15b) are downward biased because $\operatorname{Côv}\left(\boldsymbol{E}_{\boldsymbol{t}} \boldsymbol{E}_{t-1}\right)$ is positively correlated with the level of the quoted spread. Since $\operatorname{Cov}\left(\boldsymbol{R}_{\mathbf{A B n}} \boldsymbol{R}_{\mathbf{A B r}-\mathbf{1}}\right)$ is a measure of $\operatorname{Cov}\left(\boldsymbol{E}_{\boldsymbol{m}} \boldsymbol{E}_{\boldsymbol{r}-1}\right)$, we estimate the daily cross-sectional correlation between $\operatorname{Côv}\left(\boldsymbol{R}_{\boldsymbol{B B n}} \boldsymbol{R}_{\boldsymbol{A B t}-1}\right)$ and $\boldsymbol{s}_{\boldsymbol{q} \boldsymbol{x}}$. The estimated correlation is positive for firms within all portfolios. For all firms in our sample, the estimated correlation coefficient is 0.175 , with a $t$-statistic of 9.30 .

\section{Summary and Conclusions}

In this article, we show that previous estimators of both the bid-ask spread and its components are biased and inefficient. These estimators are based on the autocovariance of transaction returns, and are biased

\footnotetext{
is The alternative spread estimates, however, are still downward biased: all these estimates are significantly lower than the $\xi_{2}$ ' 3 in Table 2 . This occurs because the alternative estimates of the spread based on $\operatorname{Cov}\left(\boldsymbol{R}_{m} \boldsymbol{R}_{m-1}\right)-\operatorname{Cov}\left(\boldsymbol{R}_{m-1} \boldsymbol{R}_{m-1}\right)$ presume that all information about a security's expected return is contained in its own past return history. This is unlikely to be true. On the other hand, the $\xi_{\text {his }}$ are based on $\operatorname{Cov}\left(R D_{m} R D_{m-1}\right)=\operatorname{Cov}\left(R_{m}-R_{m, m} R_{r, r-1}-R_{m-1}\right)$, which eltminates the effects of the $E_{n}^{\prime}$ 's entrely because $E_{n}$ is contained in both $R_{n}$ and $R_{n}$. Hence, if bid/ask prices are available, we should always use the $\xi_{2}$;'s to estimate the components of the spread because all effects of the $E_{a}^{\prime}$ 's are removed, regardless of the factor(s) determining them.
} 
because these returns contain positively autocorrelated components as a result of time variation in expected returns. Since transaction returns also contain a large "unexpected" return component, these estimators are inefficient as well.

We, therefore, introduce a new approach to obtain unbiased and efficient estimators of the components of the spread. This approach relies on utilizing the information in both transaction prices and bid/ ask quotes in estimating the spread components. We use daily and weekly data of NYSE/AMEX and NASDAQ stocks and find that between 77 and 97 percent of the downward bias in previous spread estimates is due to time variation in expected returns. More importantly, though adverse selection comprises a significant component of the spread, it is a much smaller proportion (only 8 to 13 percent) of the quoted spread, at least for small trades, than the previously documented magnitude of over 40 percent. Also, there is no evidence of an inventory cost component. Therefore, order-processing costs are the predominant component of quoted spreads.

The evidence reported in this article suggests caution in drawing inferences from tests of bid-ask theories based on transaction returns. In order to obtain unbiased and precise estimates of the spread components, it is critical to eliminate any positive autocorrelation in transaction returns and to reduce the variance contributed by unexpected returns. Availability of intraday data has made it possible to conduct more powerful tests, but such data are also more likely to contain systematic patterns as a result of short-term frictions in the market. Also, the adverse-selection component of the spread is likely to be positively related to the quantity traded. Because of unavailability of data, we were unable to estimate the relation between order size and adverse selection. However, our methodology can be extended to obtain unbiased and precise estimates of this relation.

\section{Appendix A}

\section{Proof of Property Al}

Recall that

$$
R_{n n}=E_{u}+B_{u}+U_{w}
$$

and by definition

$$
\boldsymbol{\eta}_{\boldsymbol{t}}=\boldsymbol{R}_{\boldsymbol{t \pi}}-\boldsymbol{\gamma}_{\boldsymbol{t} t}-\boldsymbol{\gamma}_{\mathbf{1}} \boldsymbol{E}_{\boldsymbol{p r}}
$$

Using Equations (A1) and (A2), and under the assumption that $E_{i t}$ and $E_{p t}$ are both $\mathrm{AR}(1)$ processes with the same autoregressive parameter $\phi \in(0,1)$, we can write 


$$
\begin{aligned}
\operatorname{Cov}\left(\eta_{t r} \eta_{t r-1}\right)= & \phi \operatorname{Var}\left(E_{t u}\right)+\operatorname{Cov}\left(B_{t r} B_{t r-1}\right)+\gamma_{2,}^{2} \phi \operatorname{Var}\left(E_{p t}\right) \\
& -\gamma_{11} \phi \operatorname{Cov}\left(E_{t r-1}, E_{p r-1}\right)-\gamma_{11} \phi \operatorname{Cov}\left(E_{p t-1}, E_{t r-1}\right) \\
& -\gamma_{1 i}\left[\operatorname{Cov}\left(B_{t r} E_{p r-1}\right)+\operatorname{Cov}\left(E_{p n} B_{t r-1}\right)\right] .
\end{aligned}
$$

Since $E_{p t}$, and $B_{i t}$ are independent, the bracketed term in Equation (A3) is zero. Therefore,

$$
\operatorname{Cov}\left(\eta_{t n} \eta_{t r-1}\right)=\phi \operatorname{Var}\left(E_{d t}-\gamma_{1} E_{p t}\right)+\operatorname{Cov}\left(B_{i n} B_{t r-1}\right)
$$

Because $\operatorname{Cov}\left(\mathbf{R D}_{t n} \mathrm{RD}_{t t-1}\right)=\operatorname{Cov}\left(\boldsymbol{B}_{t n} \boldsymbol{B}_{t t-1}\right), s_{q t}=s_{2 i} \geq s_{1 t}$. The downward bias in $s_{1 i}$ decreases, to zero (i.e., $s_{1 i}$ approaches $s_{21}$ ) if the variance of the error in using $E_{p t}$ as a proxy for $\boldsymbol{E}_{\boldsymbol{t}} \operatorname{Var}\left(\boldsymbol{E}_{\boldsymbol{z}}-\boldsymbol{\gamma}_{1} \boldsymbol{E}_{\boldsymbol{p}}\right)$, decreases to zero [see Equation (A4)].

\section{Proof of Property A2}

For all numbers $\boldsymbol{\gamma}_{\mathbf{1}}>\mathbf{0}$, we have

$$
\gamma_{11}<2 \gamma_{1 r}
$$

But under the assumption that $E_{i t}$ and $E_{p t}$ are positively correlated, jointly normally distributed random variables, the true value of the regression coefficient is

$$
\gamma_{1 s}=\frac{\operatorname{Cov}\left(E_{t s}, E_{p t}\right)}{\operatorname{Var}\left(E_{p t}\right)}
$$

Substituting Equation (A6) into inequality (A5), and performing some algebraic manipulation, yields

$$
\phi \operatorname{Var}\left(E_{t t}-\gamma_{1 t} E_{p t}\right)<\operatorname{Cov}\left(E_{t i} E_{t r-1}\right) .
$$

From inequality (A7) it follows that the downward bias in $s_{i}$ is always greater than the downward bias in $\boldsymbol{s}_{\mathbf{1}}$. Hence, it is always better to filter transaction returns with $E_{p t}$ before calculating the spread estimates.

\section{Appendix B}

\section{Proof of Property B1}

From the specification of regression (15c), $\boldsymbol{\beta}_{\mathbf{2}}$ may be written as

$$
\beta_{2 t}=\frac{\operatorname{Cov}\left(\hat{s}_{2 t t} s_{q t t}\right)}{\operatorname{Var}\left(s_{q t i}\right)}=\pi_{i} \frac{\operatorname{Cov}\left(s_{q t i} s_{q t t}\right)}{\operatorname{Var}\left(s_{q t i}\right)}=\pi_{i}
$$

And, therefore, $\boldsymbol{\alpha}_{\mathbf{2} \boldsymbol{t}}$ is

$$
\alpha_{2 t}=\hat{S}_{2 t}-\beta_{2 s} S_{q t}=\pi S_{q t}-\pi S_{q t}=0 .
$$


And since least-squares estimators are unhiased, $\boldsymbol{E}\left(\hat{\boldsymbol{\beta}}_{21}\right)=\boldsymbol{\beta}_{\mathbf{2 l}}=\boldsymbol{\pi}$, and $\boldsymbol{E}\left(\hat{\boldsymbol{\alpha}}_{\mathbf{2}}\right)=\boldsymbol{\alpha}_{\boldsymbol{2}}=\mathbf{0}$. The estimators $\hat{\boldsymbol{\alpha}}_{\boldsymbol{2}}$ and $\hat{\boldsymbol{\beta}}_{\boldsymbol{2}}$ are also efficient because $\hat{\boldsymbol{s}}_{31}$ iis based on $\mathrm{RD}_{i t}$ which contains neither $E_{i t}$ nor $U_{i t}$. Hence, $\operatorname{Var}\left(\hat{\boldsymbol{\alpha}}_{21}\right)$ and $\operatorname{Var}\left(\hat{\boldsymbol{\beta}}_{2}\right)$ will be minimized. (See proof of Property B3 for details.)

\section{Proof of Property B2}

Using Equations (3) and (8), the two spread estimators, $\hat{\boldsymbol{s}}_{\boldsymbol{1}}$ and $\hat{\boldsymbol{s}}_{1 \boldsymbol{n}}$ can be written as

$$
\begin{aligned}
\hat{s}_{t t}= & 2 \sqrt{-\operatorname{Cov}\left(B_{t t} B_{t t-1}\right)} \\
& +\left[2 \sqrt{-\operatorname{Cov}\left(B_{t n} B_{t t-1}\right)}-\operatorname{Cov}\left(E_{t m} E_{t t-1}\right)\right. \\
& \left.-2 \sqrt{-\operatorname{Cov}\left(B_{t n} B_{t t-1}\right)}\right]
\end{aligned}
$$

and

$$
\begin{aligned}
\hat{S}_{1 n t}=2 & \sqrt{-\operatorname{Cov}\left(B_{t n} B_{u t-1}\right)} \\
+ & {\left[2 \sqrt{-\operatorname{Cov}\left(B_{t n} B_{t h-1}\right)-\phi \operatorname{Var}\left(E_{u t}-\gamma_{1} E_{p t}\right)}\right.} \\
& -2 \sqrt{\left.-\operatorname{Cov}\left(B_{t n} B_{t t-1}\right)\right]}
\end{aligned}
$$

We rewrite Equations (B3) and (B4) as

$$
\hat{s}_{t t}=2 \sqrt{-\operatorname{Cov}\left(B_{t m} B_{t-1}\right)}+\hat{e}_{t t}
$$

and

$$
\hat{s}_{1 t}=2 \sqrt{-\operatorname{Cov}\left(B_{\imath n} B_{t r-1}\right)}+\hat{e}_{2 r}
$$

The variables $\hat{\boldsymbol{e}}_{\| t}$ and $\hat{\boldsymbol{e}}_{1 u}$; are specification errors with nonzero means, with $\boldsymbol{E}\left(\hat{\boldsymbol{e}}_{1}\right)<\boldsymbol{E}\left(\hat{\boldsymbol{e}}_{1}\right) \leq \mathbf{0}$. This follows from Property A2.

The slope coefficients of regressions (15a) and (15b) are

$$
\beta_{i}=\sqrt{\pi_{i}}+\frac{\operatorname{Cov}\left(\hat{e}_{t i t} s_{q t t}\right)}{\operatorname{Var}\left(s_{q t t}\right)}
$$

and

$$
\beta_{11}=\sqrt{\pi_{i}}+\frac{\operatorname{Cov}\left(\hat{e}_{14 t} s_{q u t}\right)}{\operatorname{Var}\left(s_{q u}\right)}
$$

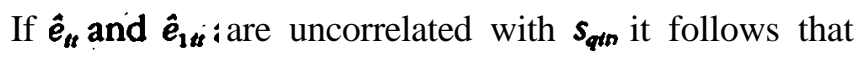

$$
E\left(\hat{\beta}_{i}\right)=\beta_{i}=E\left(\hat{\beta}_{1}\right)=\beta_{1}=\sqrt{\pi_{1}}
$$

and

$$
\alpha_{i}=\hat{s}_{t}-\hat{\beta}_{s} s_{q t}=\sqrt{\pi} s_{q t}+\hat{e}_{t}-\dot{ } \sqrt{\pi} s_{q d}=\hat{e}_{r}
$$

Similarly, $\boldsymbol{\alpha}_{\mathbf{1}}=\hat{\boldsymbol{e}}_{1}$. And from the definition of the least-squares estimators; we have

$$
E\left(\hat{\alpha}_{1}\right)<E\left(\hat{\alpha}_{11}\right) \leq E\left(\hat{\alpha}_{2}\right)=0
$$


From Property A2 it also follows that $\boldsymbol{E}\left(\hat{\boldsymbol{\alpha}}_{12}\right)=\boldsymbol{E}\left(\hat{\boldsymbol{\alpha}}_{2}\right)=0$ as the variance of the error In using $E_{p t}$ as a proxy for $E_{i t}$ decreases _ to zero.

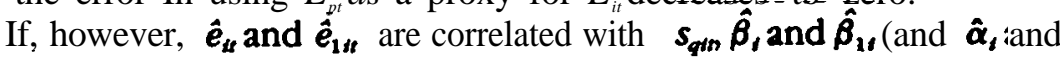
$\left.\hat{\boldsymbol{\alpha}}_{1}\right)$ will be biased. This follows directly from the formulas for $\boldsymbol{\beta}_{\boldsymbol{1}}$ and $\boldsymbol{\beta}_{\mathbf{1}}$ ( 1 (and $\boldsymbol{\alpha}_{\boldsymbol{i}}$ and $\left.\boldsymbol{\alpha}_{\mathbf{1}}\right)$. Also, note that if $E_{p t}$ is a perfect proxy for $\boldsymbol{E}_{\boldsymbol{t n}}$ no specification error will remain in $\hat{\boldsymbol{s}}_{\mathbf{1}}$ and hence $\boldsymbol{E}\left(\hat{\boldsymbol{\alpha}}_{12}\right)=\mathbf{0}$ and $\boldsymbol{E}\left(\hat{\boldsymbol{\beta}}_{1}\right)$ $=\sqrt{\pi_{r}}$

\section{Proof of Property B3}

All measures of the spread are based on first-order autocovariances. The sampling variance of the first-order autocovariance of $Y_{t}$ may be written as

$$
\operatorname{Var}\left[\operatorname{Cov}\left(Y_{n} Y_{t-1}\right)\right]=\left(1+2 \rho_{y}^{2}\right)[\operatorname{Var}(Y)]^{2},
$$

where $\boldsymbol{\rho}_{\boldsymbol{y}}$ is the true first-order autocorrelation coefficient of $Y_{t}$ [see Bartlett (1946)].

Let us compare the sampling variance of $\hat{\boldsymbol{s}}$ and $\hat{\boldsymbol{s}}_{\mathbf{2}}$. Note that $\hat{\boldsymbol{s}}$ is based on $\operatorname{Cov}\left(\boldsymbol{R}_{\boldsymbol{T}_{n}} \boldsymbol{R}_{\boldsymbol{n}-1}\right)$ and $\hat{\boldsymbol{s}}_{\mathbf{2}}$ is based on $\operatorname{Cov}\left(\mathbf{R D}_{n} \mathbf{R D}_{\boldsymbol{m}_{-1}} \mathrm{~N}\right.$ o w , $\operatorname{Var}\left(\mathrm{RD}_{\text {, }}\right.$ is likely to be much smaller than $\operatorname{Var}\left(\boldsymbol{R}_{\boldsymbol{\pi}}\right)$. For all firms in our sample, the average weekly ratio of $\operatorname{Var}\left(\mathbf{R D}_{t}\right) / \operatorname{Var}\left(\mathbf{R}_{\boldsymbol{n}}\right)$ is 0.124 . Hence, $\operatorname{Var}\left(\boldsymbol{R}_{\boldsymbol{T}}\right)$ is nine times larger than $\operatorname{Var}(\mathbf{R D}$,$) and this number$ varies between 5 (for small firms) and 15 (for large firms). This dramatic difference is largely because $U_{t}$ is the predominant source of variation in transaction returns, and $R D_{t}$ does not contain either $E_{t}$ or $U_{\text {. }}$

Hence, even if we assume that the first-order autocorrelation of transaction returns, $\boldsymbol{\rho}_{\boldsymbol{R}}$, equals 0 (minimum possible), and the firstorder autocorrelation of $\mathbf{R D}_{\mathbf{n}} \boldsymbol{\rho}_{\mathbf{R D}}$, equals -0.50 (maximum possible), we find that for all firms the weekly sampling variance of $\operatorname{Cov}\left(\boldsymbol{R}_{\boldsymbol{m}}, \boldsymbol{R}_{\boldsymbol{n}-1}\right)$ will be' about 55 times larger. than the sampling variance of $\operatorname{Cov}\left(R_{D_{n}} \mathbf{R D}_{-1}\right)$. And this difference is much greater for larger than for smaller firms. Also, since $\operatorname{Var}\left(U_{\ell}\right)$ is significantly lower in daily data, while $\operatorname{Var}(\mathbf{R D})$ remains roughly the same; the differences in daily sampling variances of $\operatorname{Cov}\left(R_{m}, R_{T-1}\right)$ and $\operatorname{Cov}\left(\mathrm{RD}_{t}, \mathrm{RD}_{t-1}\right)$ will be smaller.

Now consider $\hat{\boldsymbol{s}}_{1}$, which is based on $\operatorname{Cov}\left(\eta_{n} \eta_{r_{1}}\right)$. Even if $E_{p t}$ were a perfect proxy for $E_{i t}$ (the best-case scenario), $\eta_{z}$ would still contain $U_{t}$. And since $U_{t}$ is the predominant component of $R_{T}, \operatorname{Var}\left\{\operatorname{Cov}\left(\eta_{n} \eta_{t-1}\right)\right]$ $>\operatorname{Var}\left[\operatorname{Cov}\left(\mathbf{R D}_{n} \mathbf{R D}_{t-1}\right)\right]$. Of course, to the extent that expected returns vary through time, and that $E_{p t}$ extracts an estimate of $E_{v}$, the sampling variance of $\hat{\boldsymbol{s}}_{\mathbf{1}}$ is likely to be lower than the sampling variance of $\hat{\boldsymbol{s}}$. However, based on estimates of $\boldsymbol{\rho}_{\boldsymbol{R}}^{2} \boldsymbol{\rho}_{*}^{\mathbf{2}}$, and $\operatorname{Var}\left(\boldsymbol{\eta}_{\boldsymbol{t}}\right) / \operatorname{Var}\left(\boldsymbol{R}_{\boldsymbol{n}}\right)$, the differences in the sampling variances of $\hat{\boldsymbol{s}}$ and $\hat{\boldsymbol{s}}_{\text {, }}$ are minor: $\operatorname{Var}(\hat{\boldsymbol{s}})$ is typically 1.04 to 1.10 times larger than $\operatorname{Var}\left(\hat{\boldsymbol{s}}_{1}\right)$. 
Hence, $\operatorname{Var}\left(\hat{\boldsymbol{s}}_{2}\right)<\operatorname{Var}\left(\hat{\boldsymbol{s}}_{1}\right)<\operatorname{Var}(\hat{\boldsymbol{s}})$. And since the coefficient of determination is inversely related to the variance of the dependent variable, the $R^{2}$ 's of regression (15c) will be much larger than those of regressions (15a) or (15b). The sampling variances of 'the estimators of the parameters of the regressions, on the other hand, are directly, related to the variance of the dependent variable. Therefore, $\hat{\boldsymbol{\alpha}}_{\mathbf{2}}$ and $\hat{\boldsymbol{\beta}}_{\mathbf{2}}$ will be efficient because $\hat{\boldsymbol{s}}_{\mathbf{2}}$ is based on $\mathrm{RD}_{\mathrm{t}}$. The sampling variances of $\hat{\boldsymbol{\alpha}}$ : and $\beta$, on the other hand, will be the largest. And again, the differences in $R^{2}$ and standard errors of regressions (15a) and (15c) will be greatest for large firms, and larger in weekly versus daily data.

\section{References}

Amihud, Y., and H. Mendelson, 1980, "Dealership Markets: Market-Making with Inventory," Journal of Financial Economics, 8, 31-53.

Amihud, Y.. and H. Mendelson, 1987, "Trading Mechanisms and Stock Returns: An Empirical Investigation." Journal of Finance, 42, 533-553.

Bagehot, W., 1971. “The Only Game In Town.” Financial Analysis Journal, 27, 12-14.

Bartlett, M. S., 1946, "On the Theoretical Specification of the Sampling Properties of Autorelated Time Series." Journal of the Royal Statistical Society, 88, 27-41.

Choi, J. Y., D. Salandro. and K. Shastri, 1988, "On the Estimation of Bid-Ask Spreads: Theory and Evidence," Journal of Financial and Quantitive Analysis, 23, 219-230.

Cohen, K. J., et al., 1986, The Microstructure of Securties Markets, Prentice-Hall, Englewood Cliffs, NJ.

Conrad, J.. and G. Kaul, 1988, “Time-Variation in Expected Returns” Journal of Business, 61, 409425 .

Conrad. J., and G. Kaul, 1989, "Mean Reversion in Short-Horizon Expected Return," Review of Financial Studies, 2 ,225-240.

C\&ad, J., and G. Kaul, 1991. "Frictions and the Time Series Properties of Asset Returns," working paper, The University of Michigan. Ann Arbor.

Conrad, J., G. Kaul, and M. Nimalendran. 1990. "Components of Short-Horizon Individual Security Returns," working paper, The University of Michigan; forthcoming in Journal of Financial Economics.

Copeland, T.. and D. Galai. 1983, "Information Effects on the Bid-Ask Spread," Journal of Finance, $38, \quad 1457-1469$.

Demsetz, H., 1968, “The Cost of Transacting," Quarterly Journal of Economics 82, 33-53.

Easley, D., and M. O'Hara, 1987. "Price. Trade Size and Information in Securities Markets," Journal of Financial Economics, 19, 69-90.

Glosten, L R., 1983, "Components of the Bid-Ask Spread and the Statistical Properties of Transaction Prices," Journal of Finance, 42, 1293-1308.

Clown, L R., 1989, "Insider Trading. Liquidity. and the Role of the Monopolist Specialist," Journal of Business, 62, 211-235.

Glosten, L. R., and L E. Harris, 1988, "Estimating the Components of the Bid-Ask Spread," Journal of Financial Economics, 21, 123-142. 
Glosten, L R. and P. R. Milgrom. 1985, "Bid. Ask and Transaction Prices in a Specialist Market with Heterogeneously Informed Traders," Journal of Financial Economics, 14, 71-100.

Harris L., 1989, “A Day-End Transaction Price Anomaly,” Journal of Financial and Quantitative Analysts 24, 29-45.

Harris, L., 1990. "Statistical Properties of the Roll Serial Covariance Bid/Ask Spread Estimator," Journal of Finance, 45, 579-590.

Ho, T., and H. R. Stoll, 1981, "Optimal Dealer Pricing under Transactions and Return Uncertainty," Journal of Financial Economics 9, 47-73.

Keim, D. B., 1989, “Trading Patterns, Bid-Ask Spreads and Estimated Security Returns: The Case of Common Stocks at The Turn of the Year." Journal of Financial Economics, 25, 75-97.

Keim, D. B., and R. P. Stambaugh, 1986, "Predicting Returns in the Stock and Bond Markets," Journal of Financial Economics, 12, 13-32.

Kyle, A. S., 1985, “Continuous Auctions and Insider Trading,” Econometrica, 53, 1315-1335.

Lo, A. W, and A. C. MacKinlay, 1988, "Stock Market Prices Do Not Follow Random Walks: Evidence from a Simple Specification Test.” Review of Financial Studies, 1, 41-66.

Lo. A., and C. MacKinlay. 1990, "An Econometric Analysis of Nonsychronous Trading." Journal of Econometrics, 45, 181-211.

Niederhoffer, V., and M. P.M. Osborne, 1966, "Market Making and Reversals on the Stock Exchange," Journal of the American Statistical Association, 61, 897-916.

Roll. R., 1984, “A Simple Measure of the Effective Bid-Ask Spread in an Efficient Market.” Journal of Finance, 39, 1127-1139.

Stoll, H.R., 1989, "Inferring the Components of the Bid-Ask Spread: Theory and Empirical Tests," Journal of Finance, 44, 115-134.

Tinic, S., 1972, "The Economics of Liquidity Services." Quarterly Journal of Economics, 86, 79-93. 